\title{
The Plant Nucleolus
}

Julio Sáez-Vásquez (1) and Francisco Javier Medina (2*)

(1) Laboratoire Génome et Développement des Plantes. UMR CNRS 5096, Université de Perpignan, 52 Av. Paul Alduy, 66860 Perpignan Cedex, France. saez@ univ-perp.fr

(2) Centro de Investigaciones Biológicas (CSIC), Ramiro de Maeztu 9, 28040 Madrid, Spain. fjmedina@cib.csic.es

(*) Author for correspondence

Dr. Julio Sáez-Vásquez

Laboratoire Génome et Développement des Plantes. UMR CNRS 5096

Université de Perpignan

52 Av. Paul Alduy

66860 Perpignan Cedex, France

saez@univ-perp.fr

Phone : +33468662132

Fax : +33468668499

Dr. Francisco Javier Medina

Centro de Investigaciones Biológicas (CSIC)

Ramiro de Maeztu 9

28040 Madrid, Spain

fjmedina@cib.csic.es

Phone: +34 918373112 ext. 4261

Fax: +34 915360432

Sáez-Vásquez J, Medina FJ (2008) The Plant Nucleolus. In: Kader JC, Delseny M (eds) Advances in Botanical Research vol. 47. Elsevier, San Diego, CA, pp 1-46.

doi:10.1016/S0065-2296(08)00001-3 


\begin{abstract}
The nucleolus is a nuclear substructure that is well known as the ribosome factory of the cell, namely, the site in which the production of mature ribosomal subunits takes place before their export to the cytoplasm. The process involves the transcription of the genes encoding three of the four RNA species of ribosomes (18S, 5.8S and -in plants- 25S) as a single pre-rRNA molecule, and the processing of this molecule up to the assembly of mature rRNA species with specific ribosomal proteins. In this paper we review the progress achieved in recent years in understanding the nucleolar structure and organization of nucleolar molecular components in relation to the different functional steps of ribosome biogenesis. Furthermore, the evolution of the nucleolus through interphase and mitosis and its role in cell cycle regulation, as well as the proteinaceous factors which participate either in rDNA transcription, pre-rRNA processing and/or ribosome assembly are revised. Finally, the role played by the nucleolus and nucleolar factors in plant growth and development is also discussed.
\end{abstract}




\section{List of Contents}

THE PLANT NUCLEOLUS ...............................................................................

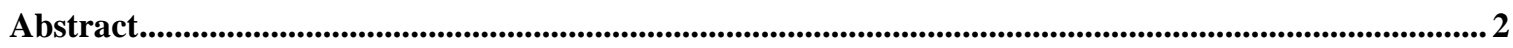

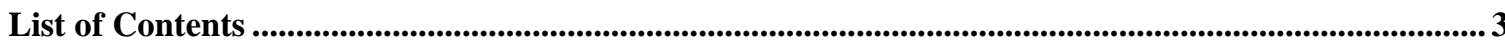

I. The structure of the plant nucleolus ......................................................................................................... 4

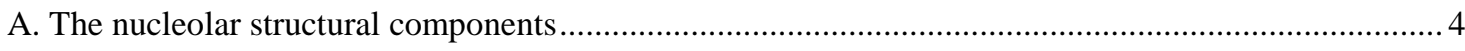

B. The structural organization of functions in the nucleolus ..................................................................

C. Transcription in the nucleolus and the identity of fibrillar centres ...................................................... 9

D. Epigenetic regulation of rRNA gene expression: gene silencing and nucleolar dominance ................ 14

II. The nucleolus during the cell cycle ................................................................................................................ 18

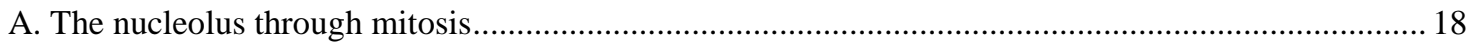

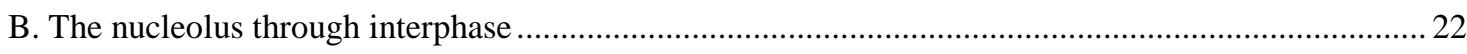

III. Nucleolar protein factors: Their role in ribosome biogenesis and plant development ..................... 25

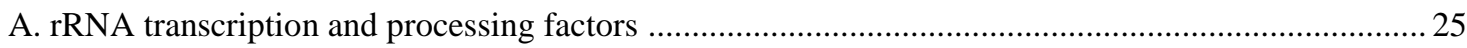

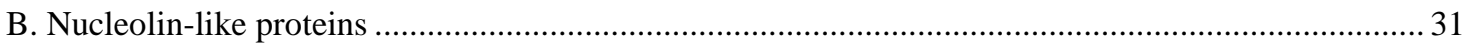

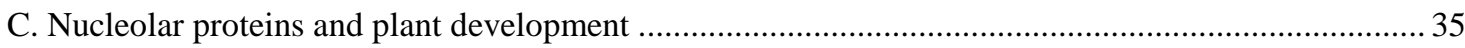

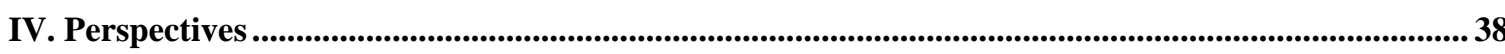

V. Acknowledgements....................................................................................................................................... 40

VI. References ............................................................................................................................................................... 41

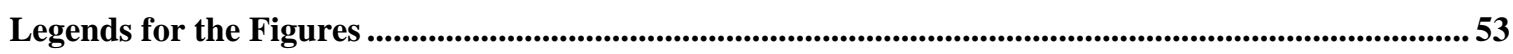




\section{The structure of the plant nucleolus}

\section{A. The nucleolar structural components}

The nucleolus is a nuclear substructure which, to use a very apt expression, "is formed by the act of building a ribosome" (Mélèse and Xue, 1995). The nucleolus is well known as the ribosome factory of the cell, that is, the site in which the production of mature ribosomal subunits takes place, before their export to the cytoplasm. The process involves the transcription of the genes encoding three of the four RNA species of ribosomes $(18 \mathrm{~S}, 5.8 \mathrm{~S}$ and -in plants25S) as a single pre-rRNA molecule, and the processing of this molecule up to the assembly of mature rRNA species with specific ribosomal proteins (Fig. 1).

\section{<Figure 1 near here>}

The nucleolus is the most outstanding example of functional nuclear compartmentalization. Within the nucleus, there are no membranes or walls capable of delimiting spaces ascribed to particular functions. However, the nucleus does show structural domains in which certain macromolecular components are recruited, to perform a precise function. The nucleolus is the most prominent example of this, because the structural organization of the territory devoted to ribosome biogenesis is a nuclear organelle distinguishable at very low magnifications under the microscope. Interestingly, compartmentalization originated in order to separate ribosome biogenesis from the rest of the nuclear functions included those other nuclear functions which needed to be set apart, at least transitorily. This probably explains the "plurifunctional nucleolus" concept, a term that owes its origin to the fact that factors apparently not playing any role in ribosome biogenesis have been repeatedly retrieved from nucleolar extracts (Andersen et al., 2005; Pendle et al., 2005; Boisvert et al., 2007). 
Despite the emergent and growing discovery of the multiplicity of cellular and nuclear functions which may have their site in the nucleolus, a detailed analysis of the structural subcomponents of the organelle can only explain the functional role of these subcomponents during the different steps in the complex process of ribosome biogenesis. In fact, the work of many different groups, using a full range of biological model systems, throughout an extended period of time, has been needed in order to reach some conclusions on the precise localization of the different steps of pre-rRNA synthesis, processing and ribosome assembly, as well as the more or less precise and univocal correlation of functional processes with structural components. At present, even though it is agreed that the nucleolus is the site of other functions besides ribosome biogenesis, the structural-functional map of the nucleolus regarding these noncanonical functions is only in the first steps of its construction. We can mention here two papers reporting the intranucleolar localization of proteins not related to pre-rRNA synthesis and processing, namely nucleostemin (Politz et al., 2005) and a reverse transcriptase related to telomere maintenance (Díez et al., 2006). Interestingly, both papers show that the localization is not strictly associated to any known subnucleolar component, and suggest that the nucleolus may be more subcompartimentalized than previously thought. Actually, the composition of such this map will probably be a long and hard task, since there is a multiplicity of functions and molecular components to localize, not necessarily related to one another, therefore requiring individual studies for each case.

The current structural dissection of the nucleolus shows a few permanent (or almost permanent) nucleolar subcomponents, namely fibrillar centres (FCs), the dense fibrillar component (DFC) and the granular component (GC), which are sometimes accompanied by other structures, such as vacuoles, interstices, etc. (Fig. 2) (Jordan, 1984). The idea supported by the majority of specialists is that all nucleoli in all model systems are built with the same structural components, having the same functional significance in all of them (Shaw and Jordan, 
1995). This idea is compatible with the enormous polymorphism exhibited by the nucleolus from one cell type to another and even within a single cell type. In some cases, it is difficult to distinguish one subnucleolar component from another, and structural transitions can be found between adjacent components. Moreover, the proportion and relative distribution of basic components may differ greatly; for instance, an active nucleolus of a plant meristematic cell contains more than $50 \%$ of $\mathrm{DFC}$, and only $1 \%$ of FCs, the rest being made up of GC and the nucleolar vacuole, whereas the active nucleolus of a mammalian cultured cell contains $75 \%$ of GC, 17\% of DFC and 25\% of FCS (Jordan and McGovern, 1981). Even when the proportion of components is similar, one can find differences in the spatial arrangement or distribution of them, such as the reticulate pattern versus the compact one, or the segregated versus the intermingled components (Shaw and Jordan, 1995). An important feature of plant FCs which is not usual in animal cell types is the existence of two structural types, namely homogeneous, similar to those found in animal cells, composed of a fibrous relatively loose material, and heterogeneous, which, in addition to the foregoing have small condensed chromatin inclusions. Homogeneous FCs are small and numerous and often appear in nucleoli active in ribosome production. Heterogeneous FCs are few and large, and are associated with low rates of nucleolar transcriptional activity (Risueño and Medina, 1986).

\section{$<$ Figure 2 near here $>$}

There are several reasons that may account for the high nucleolar structural variability. In most cases, the differences are either the result of the response to different functional requirements, or to the particular rate at which the process, as a whole or in some of its parts, is performed. This is true, for example, in the case of the varying amounts of GC exhibited by differently active nucleoli in the same organism. The explanation is that nucleoli having a high rate of rRNA gene transcription and processing, such as those of highly proliferating cells, produce large quantities of ribosomes, whose structural expression is an increased amount of 
GC. On the contrary, in differentiated cells, ribosome biogenesis proceeds at a rate low enough to support cellular metabolism in a specialized cell whose growth is rather slow. The consequence is a very reduced (and in some cases practically undetectable) GC. In other cases, the structural variability reflects quantitative variations as to the number of ribosomal genes, or the portion of these genes which are active or ready to be active (capable of being transcribed).

\section{B. The structural organization of functions in the nucleolus}

It is a general feature, observed in all model systems studied, that the molecular components of the nucleolus are organized in a vectorial fashion, from the centre outwards, forming several ultrastructural domains, in which, sequentially, pre-rRNA synthesis and processing, as well as the ribosome assembly, take place. There may be just one vectorial organization for the whole organelle, or a multiple vectorial organization forming different foci which are the result of the organization of the rDNA chromatin. In each of these foci the same vectorial organization is repeated.

The innermost nucleolar components - the "heart" of the nucleolus (Jordan, 1987) - are FCs, and that is why these nucleolar subcomponents have been associated with rDNA chromatin organization and transcription. They can be described as clear areas, when observed in electron microscope images surrounded by a darker component, the dense fibrillar component (DFC). The presence in them of RNA pol I has been reported (Scheer and Rose, 1984; Martín and Medina, 1991; Gilbert et al., 1995); however, transcriptional activity of rRNA genes, detected after Br-UTP incorporation, was only localized at the periphery of FCs, in the DFC and, notably, in the transition area FC-DFC (Dundr and Raska, 1993; De Cárcer and Medina, 1999; Cmarko et al., 2000).

Fibrillar centres are discrete structures, as revealed after three-dimensional reconstruction of the nucleolus from ultrathin serial sections (Medina et al., 1983a). Only in the case of quiescent cells, in which ribosome biogenesis is completely inactive in the residual nucleolus, do 
the individual discrete FCs actually correspond to sections of a continuous channel or cord, extending throughout the nucleolus, from side to side (Risueño and Medina, 1986). Depending on the nucleolar structural pattern, they are connected by DFC strands, or immersed in DFC masses. Whatever the case, there is rDNA that extends through the DFC between FCs, and this rDNA is actively transcribing. The FC-connecting DNA was detected first by using an anti-DNA antibody (Martín et al., 1989) and the selective cytochemical staining of DNA using osmium ammine confirmed the existence of these extended DNA filaments (Motte et al., 1991). Threedimensional reconstruction from confocal optical sections after transcription in situ revealed the transcriptional activity of these DNA fibres (De Cárcer and Medina, 1999). In animal cells, partially disorganized nucleoli after treatment with 5,6 dichloro-b-ribofuranosyl benzimidazole (DRB) show necklace-like structures in whose "beads" FC-like structures can be identified and transcription detected. The observation that single beads are linked by the DFC (Panse et al., 1999), supports the existence of active DNA connecting FCs.

The dense fibrillar component (DFC) is the site of pre-rRNA processing, and several RNAs, intermediaries in the different processing steps, were retrieved from the DFC as reported in a pioneer work (Royal and Simard, 1975). Furthermore, radio-labelled pre-rRNA precursors were detected in the DFC by using autoradiographic techniques (Fakan and Puvion, 1980) and, in more recent works, by using Br-UTP labelling. Modern microscopical methodologies have confirmed these conclusions (Thiry et al., 2000). The same methods have localized late prerRNA processing and preribosome assembly in the granular component, constituted by numerous granules, around $15 \mathrm{~nm}$ in size.

Finally, the nucleolar vacuole is a feature of those plant nucleoli which show a very high rate of transcriptional and processing activity, typically in proliferating cells at the G2 stage of the cell cycle (Moreno Díaz de la Espina et al., 1980; Deltour and De Barsy, 1985; GonzálezCamacho and Medina, 2006). 


\section{Transcription in the nucleolus and the identity of fibrillar centres}

The nucleolus results from the expression of a segment of the genome, i.e. the set of ribosomal genes, or rRNA genes, or rDNA (Fig. 1). Thus, the nucleolar structure is the result of a sequence of cellular activities which are triggered by the organization and assembly of the transcription complex on rDNA, in order to produce transcription of ribosomal genes by RNA polymerase I. Therefore, an effective approach to unequivocally identify the nucleolar substructures associated with transcription is to follow the generation of a new nucleolus, starting from situations or conditions in which the nucleolus either does not exist, or it is totally inactive, up to when it becomes a fully active organelle. This process, generally termed "nucleologenesis" can be found, for example after mitosis, when the nucleolus is organized in each of the two daughter cells around the segment of chromosomes containing rRNA genes, called the "nucleolar organizing region" or "nucleolar organizer" (NOR). Details of the molecular mechanisms involved in nucleologenesis at the end of mitosis will be extensively considered in the next section; here we will focus on the process of nucleolar structure growth, associated with the resumption of nucleolar activity, particularly rDNA transcription.

Actually, postmitotic nucleologenesis is a quick process, in which the precise establishment of a sequence of events is a difficult task, so that the generation pathway of each of the nucleolar subcomponents, and its association with precise nucleolar functions, is nearly impossible to follow. Fortunately, plant cells offer us a model in which all these events occur at such a slow pace that they are capable of being followed step by step, so that the structural variations of nucleolar subcomponents can be associated with a single functional process. The model referred to is the postmeiotic interphase occurring in the anther. Meiosis in the anther is the first event leading to the formation of the male gametes, and meiosis produces cells called microspores, which undergo an extremely long interphase (five days or more), prior to the formation of the pollen grain. In these microspores, nucleolar activity (and, particularly, 
transcription) is resumed at a very slow rate (Medina et al., 1983b). Structurally, young Allium cepa microspores have a rather small nucleolus formed by two fibrillar balls, whose structure is the same as that of the DFC. These balls of DFC are symmetrically arranged on both sides of the NOR, which, in ultrathin sections, has a cord-like shape, and whose structure totally resembles that of the heterogeneous FCs, i.e. it is composed of small inclusions of condensed chromatin, embedded in a fibrous material, lower in electron density (Esponda and Giménez-Martín, 1974; Medina et al., 1983b) (Fig. 3). Interestingly, when a collection of ultrathin serial sections is examined in order to get the three-dimensional perspective, the shape of the NOR appears as a dish, or flattened cylinder (P. Esponda, personal communication). The response of this nucleolar organization, as the rDNA transcription activity develops at an increasing rate, is to enlarge the size of the DFC balls and to progressively decondense the NOR chromatin inclusions. (Fig. 3). During later stages, the DFC masses are infiltrated with chromatin, with the resulting appearance of FCs in their interior, and the disappearance of the cord-shaped NOR. Coinciding with the start of the formation of GC, the DFC balls progressively fuse and the nucleolar structure resembles more and more the "classical" structure of a meristematic cell nucleolus (Medina et al., 1983b). The application of the EDTA regressive cytochemical staining during the young microspore stage results in the bleaching of condensed chromatin inclusions in the NOR and the preferential staining of RNA fibres (Esponda and Giménez-Martín, 1974) (Fig. 3). These fibres are the first evidence of transcription of rRNA genes in the NOR, and they can be found intermingled with the components of the NOR structure resembling the heterogeneous FC. The RNA composition of these fibres is evidenced by their removal with RNase treatment of ultrathin sections (Fig. 3). Important conclusions regarding the nucleolar structures associated with transcription can be reached by re-evaluating and re-interpreting the results obtained in this pioneer experiment in the light of our present knowledge of the nucleolus. First of all, these results reveal that transcription actually starts in the NOR, which shows a structure totally identifiable with heterogeneous FCs. 
Furthermore, it becomes evident that there is a continuity between the chromosomal NOR and nucleolar FCs, and between heterogeneous FCs and homogeneous FCs. If these data are extrapolated to the "classical" interphase nucleolus, a conceivable interpretation would be that transcription actually begins inside FCs, but is not usually detected at these internal locations because DFC generation is such a quick process that transcription can only be visualized together with its product, i.e. in the DFC or, on fortunate occasions, in the FC-DFC boundary.

\section{<Figure 3 near here>}

Direct research on the localization of transcription in onion meristematic cell nucleoli in interphase (a suitable largely used plant model) began by the quantitative immunolocalization of DNA and RNA pol I in onion nucleoli, which led to the definition of the transition area between FCs and the DFC as a significant nucleolar domain. The interpretation of the immunocytochemical results, which also took into account the former autoradiographic data, strongly pointed to this domain as the site of rDNA transcription (Martín et al., 1989; Martín and Medina, 1991). Really, the differences between the site in which transcription occurs and the site in which it is detected, due to technical limitations, were pointed out in these papers, where we can read: “...transcription actually begins in fibrillar centres, but, as an immediate result, a dense fibrillar component is gradually generated, giving rise to a structural transition area between the two components." (Martín and Medina, 1991). Further studies, in some cases using the in situ run-on technique, consistently showed the transcription marker in a restricted nucleolar area made up of the outer periphery of FCs and the inner periphery of the DFC, thus supporting the results obtained in the onion model (Testillano et al., 1994; Shaw et al., 1995; Melcák et al., 1996).

The use of Br-UTP incorporation in isolated onion cell nuclei, combined with the immunodetection of the nucleolar protein fibrillarin, chosen as a marker for the early processing events, together with observations under both the confocal and the electron microscopes, 
evidenced a focal arrangement of the transcription sites in the nucleolus. Most of these foci were located at the periphery of FCs, while the core of every FC appeared devoid of labelling, either by the RNA precursor, or by fibrillarin. Transcription foci did not totally surround FCs, so that transcription occurred at discrete points in the boundary domain between FCs and the DFC. Regarding colocalization between transcription and fibrillarin, it was only partial in transcription foci, since fibrillarin was not found in the zones of foci immediately bordering FCs. Finally, other transcription foci were found deep in the DFC, in zones located between FCs (De Cárcer and Medina, 1999; Medina et al., 2000). At this point it is worth noting that the identity of FC structures in plant cells was unequivocally established by electron microscopy. Actually, the focal organization of nucleolar transcription had also been shown previously in other plant models (Thompson et al., 1997), but the relationship of these foci with FCs was questioned. Later on, Br-UTP incorporation was detected in pea nucleoli using pre-embedding labelling and three-dimensional electron microscopy of entire nucleoli (González-Melendi et al., 2001). Labelling, observed as clusters of particles, was claimed to represent single transcription units, or "Christmas trees" located on the DFC, but no indication was given as to where FCs would be situated. The authors argued that FCs would not play any role either in the organization of rDNA, or in the structural basis of rDNA transcription. According to their interpretation, actively transcribing rDNA would be a continuous extended loop, emanating from the condensed rDNA chromatin adjacent to the nucleolus, and running through the DFC, without any relationship with FCs (González-Melendi et al., 2001). The basis for this interpretation, however, was the discrimination of the structures underlying particle clusters; the authors claimed that there was only DFC beneath the particles, though there could also be FCs; actually, in our opinion, the preembedding method used does not provide enough quality of ultrastructural preservation to allow a precise identification. Moreover, we think that many previous results obtained in different plant models, are hardly compatible with the model proposed by these authors, among them a highly 
relevant result obtained in the same laboratory reporting the focal organization of rRNA genes, which, following in situ hybridization, were observed structured as intranucleolar spots corresponding to FCs (Rawlins and Shaw, 1990).

The nucleolus is indeed organized from a loop of rDNA emanating from the nucleolar organizer chromosome (Fig. 1), as postulated many years ago. Godward (1950), after observing the nucleolar structure of the alga Spyrogyra, called the continuous pathway followed by rDNA through the bulk of the nucleolus the "nucleolar organizer track". According to many research data, this continuous loop is not totally extended, because, in some places, the nucleolus shows focal concentrations of highly folded rDNA, which are FCs (Fig. 1). The concept of FCs as foci containing local concentrations of DNA has been supported by cytochemical experiments of selective staining of DNA (Risueño et al., 1982; Motte et al., 1991; Testillano et al., 1991), immunocytochemistry (Martín et al., 1989), and in situ hybridization (Rawlins and Shaw, 1990). The presence in plants of the so-called "heterogeneous FCs", containing small inclusions of condensed chromatin (Risueño et al., 1982) gives additional support to this concept. Heterogeneous FCs are the same structures that were called "lacunae” by Chouinard (1970) in one of the pioneer works on the localization of nucleolar DNA. Even prior to the introduction of in situ hybridization methods, there was overwhelming experimental evidence in favour of the presence of rDNA in these structures, based only on their structural identity and continuity with the secondary constriction of chromosomes, the known site of the nucleolar organizer (Medina et al., 1983b; 1983c). There is also experimental evidence to lend support to the conversion of the heterogeneous FCs into homogeneous FCs, as shown previously for microspores (Esponda and Giménez-Martín, 1974; Medina et al., 1983b), and as reported for the germination of seeds or bulbs (Deltour, 1985). This concept of FCs is compatible with data postulating the existence of a nucleolar matrix, or nucleolar proteinaceous skeleton (Moreno Díaz de la Espina, 1995), with, among other functions, that of gathering rDNA in FCs, and structurally organizing it depending 
on the nucleolar transcriptional activity and cell requirements. Certainly, however, the agreement on these concepts is not total.

\section{Epigenetic regulation of rRNA gene expression: gene silencing and nucleolar dominance}

Expression of rRNA genes is regulated at multiple levels. Transcription by RNA pol I, the further transcript processing and the final preribosome assembly and export are regulated by modulating the rate at which each individual process takes place. This regulation is achieved by mechanisms involving the participation of different factors, most of them proteinaceous. The whole chapter III of this paper is devoted to review the identity of these factors and their functional role. However, there is a second form of regulation, which acts as an "on/off" switching mechanism, producing the more or less permanent silencing of large groups of rRNA genes. This mechanism has a structural counterpart, namely the structure of the rDNA chromatin, and, in particular, its condensation state, so that silenced genes are characterized by the presence of condensed chromatin structures, whereas "open" genes display decondensed chromatin conformations.

Many reports, using a wide range of experimental approaches, can be found in the literature dealing with this process. The identification, in plant cells, of the heterogeneous type of FCs, containing small inclusions of condensed chromatin, which has just been discussed in the preceding section, is an example of the visualization of switched-off rRNA genes. As indicated above, this mechanism is fully reversible, and inter-conversions between the condensed and decondensed forms of chromatin inside FCs occur throughout different biological processes, and even throughout the different periods of the cell cycle.

The presence of rDNA chromatin under the form of heterochromatin has also been visualized in plant cells at the microscope as the so-called "nucleolus-associated chromatin" (NAC). This NAC usually appears as a large heterochromatic mass, located at the periphery of the nucleolus, showing fibers that interconnect it with the interior of the nucleolar body. The fact 
that NAC is constituted by rDNA chromatin was unequivocally demonstrated by in situ hybridization (Rawlins and Shaw, 1990; Highett et al., 1993). The same as it was shown for heterogeneous FCs, inter-conversions between the condensed and the decondensed state of chromatin affecting NAC were reported, mostly throughout the germination process (Deltour, 1985).

Otherwise, the use of psoralen photocrosslinking of rDNA in a wide variety of biological model systems, including plants, led to the conclusion that in intact cells, two distinct types of ribosomal chromatin structures coexist, one that contains nucleosomes and represents the inactive copies and one that lacks a repeating structure and corresponds to the transcribed genes. In particular, in plant cells (tomato) the nucleosome-containing chromatin is present in the majority (approximately $80 \%$ ) of the rDNA chromatin, only a minor chromatin population (approximately $20 \%$ of the ribosomal genes) being in an open configuration. Interestingly, the relative amounts of the two types of structures are similar in interphase and metaphase, but their transcriptional activities, evaluated by run-on, differ significantly. Also, these relative amounts are similar in stationary and exponentially growing cells. This suggests that the two states of chromatin are maintained independently of the transcriptional process and that they are stably propagated through the cell cycle (Conconi et al., 1989; 1992). An exception to this rule was found in yeast, which can modulate the proportion of active (non-nucleosomal) and inactive (nucleosomal) rRNA gene copies in response to variations in environmental conditions, which suggests that, unlike vertebrate and plant cells, yeast can regulate rRNA synthesis by varying the number of active gene copies (Dammann et al., 1993).

Silencing of rDNA chromatin also occur in an intriguing phenomenon called nucleolar dominance, initially discovered in a classical work performed on plant cells. This phenomenon has received much attention from leading research groups in recent years, and presently concentrates most of the efforts directed towards discovering the molecular mechanisms 
supporting the regulation of the expression of rRNA genes by on/off switching, affecting rDNA chromatin structure.

Nucleolar dominance was discovered in interspecific hybrids of Crepis by Navashin (1934), who called it "differential amphyplasty". The finding was that, in hybrids, the secondary constrictions were absent from chromosomes inherited from one species. Navashin observed that the secondary constrictions reappeared in progeny when karyotypes recovered the initial "pure species", indicating the reversibility of the phenomenon and the conservation of the integrity of the apparently absent secondary constrictions.

Nucleolar dominance was clearly evidenced by the cytochemical procedure of silver staining of the nucleolar organizer (AgNOR method). Interspecific hybrids, such as Triticale, showed silver staining in those NORs displaying secondary constrictions, whereas the underdominant NORs, lacking secondary constrictions, did not show AgNOR staining (Lacadena et al., 1984). Since AgNOR staining was interpreted in terms of rDNA chromatin structure, as an efficient and reliable labeling of decondensed forms of this chromatin (Hernandez-Verdun et al., 1982; Medina et al., 1983c; 1984), the interpretation was that underdominant NORs had repressed their expression by means of a heterochromatinization process (Medina et al., 1984). Actually, the persistence of the decondensed form of chromatin in visible secondary constrictions in chromosomes (either in hybrids or in "pure species"), in a phase in which all the rest of chromatin is fully condensed in nucleosomal and supranucleosomal configurations, is caused by the persistence of RNA pol I complex, including transcription factors, associated with rRNA genes during mitosis (see chapter II, section A in this paper).

The inactivation of a subset of rRNA genes via heterochromatinization and its reversibility strongly pointed to the consideration that nucleolar dominance was an epigenetic phenomenon, i.e. a heritable, but potentially reversible condition of gene activity that is not caused by changes in gene sequence (Preuss and Pikaard, 2007), and highly stimulated the 
research efforts looking for the molecular mechanisms responsible for this special form of gene silencing. The first decisive contributions came from the group of R.B. Flavell and their findings on the correlation of rDNA methylation and the transcription potential of rRNA genes; dominant, very active loci have a higher proportion of rRNA genes with unmethylated cytosine residues in comparison with recessive and inactive loci (Flavell et al., 1988). Furthermore, Thompson and Flavell (1988) demonstrated in wheat the existence of a correlation between nucleolar dominance, rDNA undermethylation and decondensed structure of ribosomal chromatin, this latter evaluated by its sensitivity to DNase I. Additionally, direct evidence that cytosine methylation is closely associated with rRNA gene expression and nucleolar dominance was given by experiments of plant growth in the presence of 5-aza-2'-deoxyciytidine (aza-dC), a potent inhibitor of cytosine methylation, which caused the silent, underdominant genes to become expressed to high levels (Chen and Pikaard, 1997; Lawrence et al., 2004).

However, rDNA methylation was not the unique mechanism responsible for nucleolar dominance. A treatment with histone deacetylase inhibitors, such as sodium butyrate or trichostatin A (TSA) produced similar de-repressing effects as those observed upon treatment with aza-dC (Chen and Pikaard, 1997; Lawrence et al., 2004). Furthermore, other modifications of histones were shown to play a role in nucleolar dominance; in particular, nucleosomes associated with the promoter regions of underdominant genes appeared enriched in histone $\mathrm{H} 3$ dimethylated on lysine 9 (H3K9me2), a known mark of heterochromatin, whereas promoter regions of dominant genes associated with $\mathrm{H} 3 \mathrm{~K} 4 \mathrm{me} 3$, a mark of euchromatin, and also with H3K9me2, supporting the idea that, among dominant rRNA genes, both forms of chromatin (euchromatin and heterochomatin) may coexist. As expected, a close correlation was found between DNA methylation and $\mathrm{H} 3 \mathrm{~K} 9 \mathrm{me} 2$, on the one side, and between DNA hypomethylation and H3K4me3, on the other side (Lawrence et al., 2004). Therefore, DNA methylation and histone modification states are interdependent and mutually reinforcing. 
An important question affecting not only to the phenomenon of nucleolar dominance, but also to rRNA gene silencing processes in general, is whether silencing is regulated taking the full NOR as a single locus, or regulation is exerted on single genes, one by one (or small subsets of genes). Certainly, the choice of which NORs to inactivate is not at random, but it does not depend on the number of rRNA genes, or on particularities of a given species. Some experiments with Xenopus using injected plasmid-encoded rRNA minigenes apparently demonstrated that dominance was due to differences in binding affinity of one or more limiting transcription factors to the enhancers (Reeder and Roan, 1984). However, analogous tests in plants failed to reveal these differences, since, under natural conditions, transcription factors are not a limiting component for the efficiency of transcription (Preuss and Pikaard, 2007). An interesting study using Arabidopsis thaliana inter-ecotype hybrids revealed that a certain combination of NORs from the two ecotypes involved was selected, the same in all cases, despite the fact that rRNA gene sequences are $>95 \%$ identical across $A$. thaliana ecotypes. These data do not fit into models in which nucleolar dominance is regulated at the level of individual rRNA genes, but they point to larger scale regulation of the NORs (Lewis et al., 2004; Preuss and Pikaard, 2007). Nevertheless, concluding evidence on this question has not yet been provided; further research on this topic will contribute to explain the establishment and maintenance of gene dosage levels through multiple cell generations.

\section{The nucleolus during the cell cycle}

\section{A. The nucleolus through mitosis}

When entering mitosis, during the $\mathrm{G} 2 / \mathrm{M}$ transition, the nucleolus is progressively disassembled, more or less at the same time as the nuclear envelope breaks down. Nucleolar disassembly begins with the disaggregation of the GC, and the export of the nucleolar granules 
to the cytoplasm, and continues with the progressive dispersion of the DFC between the condensed chromatin masses, until the nucleolar structure is lost in prometaphase. Functionally, this process of disassembly is accompanied by the cessation of transcription and processing. At the time of chromosome formation, in metaphase, the chromosomal locus occupied by ribosomal genes can be easily detected in the form of the secondary constriction, a species-specific zone of one or more chromosomes, cytologically characterized by a negative response to DNA staining techniques such as Feulgen and DAPI, and by a positive response to staining by a specific silver method known as Ag-NOR. The absence of staining by DAPI or Feulgen is due to the decondensed state of the chromatin in this chromosomal region whereas staining by the Ag-NOR technique is caused by the presence of some specific proteins which remain associated with rDNA chromatin. Apart from the NOR, some other nucleolar remnants can also be detected in metaphase and anaphase as sheath-like structures located at the chromosome periphery. At the end of mitosis, the nucleolus is reconstituted in the daughter cells. Nucleologenesis includes the formation of prenucleolar bodies (PNBs) from the nucleolar materials carried by the chromosomes at their periphery. The materials forming PNBs are recruited at the NOR and, together with de novo pre-rRNA synthesis, lead to the formation of the new nucleolus (Fig. 4) (Moreno Díaz de la Espina et al., 1976; De la Torre and Giménez-Martín, 1982; Azum-Gélade et al., 1994; Hernandez-Verdun and Gautier, 1994; Medina et al., 2000; Hernandez-Verdun, 2006). $<$ Figure 4 near here $>$

The components of the RNA pol I transcription complex remain assembled and associated with rDNA chromatin throughout mitosis in the NOR. In mammalian cells, there is experimental evidence of the localization of the following in this chromosomal locus: RNA pol I (Scheer and Rose, 1984), topoisomerase I (Rose et al., 1988), the transcription factors UBF and SL1 (Roussel et al., 1996; Prieto and McStay, 2005) and the termination factor TTF-1 (Sirri et al., 1999). However, this complex is kept inactive throughout all phases of mitosis, and it is only 
at the time of nucleologenesis that the transcriptional activity is resumed as one of the factors triggering the formation of the new nucleolus. Therefore, the complex is kept either inactive or active as a result of the action of regulatory factors. Among these factors, the CDKA (or CDK1, or cdc2) /cyclin B complex has been shown to play a major role by a mechanism of reversible phosphorylation (Heix et al., 1998; Sirri et al., 2000). This complex, which has a kinase activity, is a central element in the regulation of $\mathrm{G} 2 / \mathrm{M}$ transition, as already demonstrated in animals, plants and yeast (Arellano and Moreno, 1997; Dorée and Hunt, 2002; Inzé and De Veylder, 2006).

With regards to the nucleolar processing complex, investigations were performed in plant cells to find out whether the components of this complex could remain somehow assembled whilst mitotically inactive and separated from the transcription complex. In fact, the existence of components of this processing complex in the nucleolar remnants located at the periphery of chromosomes in metaphase and anaphase had been proposed (Risueño and Medina, 1986). With this in mind, the mitotic course of pre-rRNA and the nucleolar proteins fibrillarin and nucleolin was traced in onion root cells. The identity of pre-rRNA was confirmed by in situ hybridization and the time of its production, precisely at the preceding G2, was demonstrated by pulse-chase autoradiography on synchronized cells after tritiated uridine incorporation at this point of the cell cycle. Co-localization of this pre-rRNA and of the nucleolar proteins fibrillarin and nucleolin was detected in the chromosome periphery (perichromosomal sheath) during metaphase and anaphase, in irregular fibrillar masses located among chromosomes in ana-telophase, in PNBs during telophase, and in the newly formed nucleoli after nucleologenesis, indicating the simultaneous presence of components of processing complexes from the preceding interphase, in all these structures. Therefore, the perichromosomal sheath is the precursor structure of prenucleolar bodies, and this finding shows the continuity of these nucleolar molecular components through successive cell generations (Fig. 4). Colocalization of key elements of the 
pre-rRNA processing complex in the same transient structures during mitosis strongly suggests that at least a subset of these complexes do not disaggregate during cell division, but remain assembled and become incorporated into the new nucleolus (Medina et al., 1995).

In mammalian cells, proteins involved in pre-rRNA processing, as well as pre-rRNA processing intermediates, synthesized in the preceding G2, were also localized at the periphery of chromosomes during mitosis, as a result of nucleolar dispersion in prophase, and were then shown to be concentrated in PNBs at telophase (Gautier et al., 1994; Dundr and Olson, 1998; Angelier et al., 2005). Subsequently, a flow of materials is established between PNBs and the NOR, so that PNBs become progressively smaller whereas the new nucleolus emerges and grows at the site of the NOR (Savino et al., 2001). Interestingly, nucleolar protein recruitment at the NOR occurs sequentially, the early processing proteins being recruited first on transcription sites, while late processing proteins, remain in $\mathrm{PNBs}$ for a longer time, before migrating to the NOR (Savino et al., 2001). The assembly of proteins and RNA in processing complexes in the different structures in which they are localized during mitosis was analyzed in mammalian cells by fluorescence resonance energy transfer (FRET) between fluorochrome-tagged proteins (Angelier et al., 2005). FRET was not detected at the periphery of chromosomes, but it was registered in PNBs at a progressively higher rate as telophase proceeded. The interpretation was that processing complexes were not assembled in the perichromosomal sheath, but in PNBs, from which they were exported to the NOR (Angelier et al., 2005; Hernandez-Verdun, 2006). Actually, nothing is known of protein interaction with pre-rRNA in the different transitory mitotic structures, and the formation of pre-rRNP complexes, and the possibility exists that they may not be totally identifiable with those found in interphase. In fact, processing complexes, active in interphase, are inactivated in mitosis and become active again during/after nucleologenesis. In any case, all data reported up to now, in different model systems, agree in 
attributing to PNBs a central and crucial role in postmitotic nucleolar reassembly and reactivation.

The synchronization of the postmitotic nucleolar assembly with the resumption of rDNA transcription is again under the control of cell cycle regulators. These events at the NOR occur at the time when degradation of cyclin B1 and a decrease in CDKA activity overcome the mitotic repression of RNA pol I transcription (Clute and Pines, 1999; Sirri et al., 2002).

\section{B. The nucleolus through interphase}

It has been experimentally verified that, under normal physiological conditions, cell proliferation is accompanied by an increase in the biosynthesis of ribosomes (Hannan and Rothblum, 1995; Baserga, 2007). The rate of pre-rRNA transcription and processing has been shown to change progressively through the successive interphase periods. Thus, whereas in G1 the rate of these processes is kept at moderate levels, G2 is a period characterized, in general, by an intense rate of nucleolar activity (i.e., the rate of pre-rRNA transcription and transcript processing), although the values reached by the transcription and processing rates are variable in the various cell systems investigated (Kwiatkowska and Maszewski, 1979; Risueño and Medina, 1986; Klein and Grummt, 1999; Raska et al., 2004). The precise mechanisms by which transcription of rRNA genes is regulated in a cell cycle-dependent manner are now beginning to be understood, mostly in mammalian cells and in yeast. Together with the aforementioned role played by CDKA/cyclin B in mitosis (Heix et al., 1998; Sirri et al., 2000), CDK/cyclin complexes are also capable of phosphorylating the transcription factor UBF, and this phosphorylation is responsible for the increase in rDNA transcription during G1 progression (Voit et al., 1999). Moreover, there is more and more evident that the correct progression of ribosome biogenesis is a factor influencing cell cycle regulation, in such a way that, in one or more cell cycle checkpoints, the status of ribosome production is sensed and cell cycle progression is allowed or arrested in response to this stimulus. This is true in the case of the 
nucleolar protein Bop1, a regulator of pre-rRNA processing, whose alteration induces a rapid cell cycle arrest which is p53 dependent. Thus, p53 could act as a sensor of nucleolar stress caused by defects in ribosome biogenesis (Lapik et al., 2004). It is worth remembering that p53 is a tumor suppressor whose effect is to induce a G2/M arrest by decreasing intracellular levels of cyclin B1, acting at the level of gene expression (Innocente et al., 1999). In other cases, proteins have been identified that control, simultaneously, ribosome biogenesis and cell cycle progression. This is the case of pescadillo, whose mutation results in cell cycle arrest and inhibition of preribosome maturation (Lerch-Gaggl et al., 2002), or the nucleolar conserved protein SURF-6, whose depletion causes G1 arrest (Polzikov et al., 2007). Unfortunately, the knowledge we have of all these mechanisms and factors in plant cells is not as high as that of animal cells and yeast. However, little doubt exists that they are conserved through the whole phylogenetic scale, including plants, as has been shown in recent works (Zografidis et al., 2007).

The reason why there is a close relationship between cell cycle regulation and ribosome biogenesis regulation can be found in the metabolic requirements of actively proliferating cells. Cell proliferation requires continuous building of cellular materials, particularly proteins, in order to reach the critical size which will permit cell division (Baserga, 2007; Bernstein et al., 2007). Since the function of ribosomes is the translation of mRNA into proteins, the control of ribosome biogenesis is, necessarily, a key element of proliferation control (Bernstein and Baserga, 2004).

The positive correlation between cell proliferation and the activity of pre-rRNA transcription and processing causes alterations in the size of the nucleolus and in the distribution of the nucleolar components, correlated with modifications in the proliferative state of the cell. In fact, differences in ribosome synthesizing activity are expressed as morphologically detectable changes in the nucleolus (Shaw and Jordan, 1995; Thiry and Goessens, 1996; Medina et al., 2000). Since, as indicated above, each period of the cell cycle is associated with a particular rate 
of pre-rRNA synthesis and processing, it is possible that a particular structural pattern of the nucleolus could be ascribed to each interphase period. If this were so, these structural changes could serve as an excellent model for the establishment of general patterns of structure-function relationships in the nucleolus, and these nucleolar structural patterns could become excellent markers for identifying cell cycle periods. Despite these possibilities, studies dealing with the variations in nucleolar structure associated with cell cycle periods are really scarce (SacristánGárate et al., 1974; Junéra et al., 1995).

A sequential analysis of nucleolus structural variations during the different periods of interphase has been carried out in onion root meristematic cells, synchronized by a treatment with hydroxiurea (HU) followed by growth in a medium from which the drug was removed. Four different structural models were defined, associated respectively with G1 (one model), S (one model) and G2 (two models) (González-Camacho and Medina, 2006) (Fig. 5). In agreement with the well-known correlation between nucleolar size and activity, an enlargement of the nucleolus was observed from the beginning to the end of interphase, but the nucleolar size remained practically unaltered throughout G1 and S, and it was only in G2 that a dramatic increase was observed, coinciding with the peak of nucleolar activity.

\section{$<$ Figure 5 near here $>$}

Looking at particular nucleolar subcomponents, a correlation of the structure, number and size of FCs with nucleolar activity had been previously defined (Risueño et al., 1982; Medina et al., 1983a). In agreement with these data, cell cycle progression was found to be associated with an increase in the number of FCs and the reduction of their size. Structurally, heterogeneous FCs were found to be present in G1, but disappeared progressively in S, so that G2 nucleoli practically contained only homogeneous FCs (Fig. 2). In general, the structure and morphometrical parameters of the different nucleolar subcomponents could be defined in each of the interphase periods, showing a specific arrangement (Fig. 5). 


\section{Nucleolar protein factors: Their role in ribosome biogenesis and plant development}

Genome sequencing programmes in Arabidopsis (The Arabidopsis Genome Initiative, 2000) and other plant species (International Rice Genome Sequencing Project, 2005) and the homology of proteins from yeast and/or animals, has permitted the identification of a large number of putative nucleolar protein factors involved in ribosome biogenesis and/or other nucleolar functions. Recently, using a sizeable proteomic approach Pendle and co-workers carried out a comprehensive analysis of nucleolar proteins in Arabidopsis (Pendle et al., 2005) which led to the identification of 217 nucleolar proteins (Brown et al., 2005). However, this number is relatively low compared with the approximately 700 proteins identified in the human nucleolus (Leung et al., 2006), indicating that there are perhaps other stable and/or transitory unknown nucleolar proteins in plants. Nevertheless, the study performed by Pendle et al. revealed that nearly $40 \%$ of all nucleolar proteins are ribosomal proteins (RP proteins), nucleolar factors or C/D and H/ACA small nucleolar ribonucleoproteins (snoRNPs) (Brown et al., 2005), thus confirming that the major function of the nucleolus is ribosome biogenesis.

What do we know about the molecular function of these factors? How do they influence growth and plant development? To address these major questions, in the following sections we will describe some of the major advances made concerning nucleolar factors involved in rRNA synthesis and snoRNP biogenesis.

\section{A. rRNA transcription and processing factors}

As mentioned above, the primary function of the nucleolus is the transcription and processing of pre-rRNA. These two processes involve a large number of nucleolar protein factors including an RNA polymerase I enzyme and a subset of transcriptional and pre-RNA 
processing factors, all directed towards producing mature $18 \mathrm{~S}, 5.8 \mathrm{~S}$ and $25 \mathrm{~S}$ rRNA (Fig. 1) (Olson, 2004; Saez Vasquez and Echeverria, 2006).

In plants, little is known about the different transcription factors associated with the rRNA transcriptional machinery. For instance, early biochemical and immunological characterization revealed that Brassica oleracea RNA pol I is an approximately $600 \mathrm{kDa}$ multimeric enzyme complex of around 12-15 subunits (Guilfoyle et al., 1976; Guilfoyle and Jendrisak, 1978; Guilfoyle and Malcolm, 1980). Since then, many efforts to identify Pol I transcription factors have relied on gel mobility shift assays to detect proteins interacting with the rDNA promoter, but the identity of these proteins remains unknown (Sáez-Vásquez and Echeverría, 2006). The subsequent description and purification of an RNA polymerase I holoenzyme complex from Brassica oleracea in the laboratory of C. Pikaard allowed the identification of an associated casein kinase II (CKII) and histone acetyl transferase (HAT) (Sáez-Vásquez and Pikaard, 1997; Sáez-Vasquez and Pikaard, 2000; Sáez-Vásquez et al., 2001). Similar results were observed in RNA pol I holoenzymes from a mouse (Seither et al., 1998; Hannan et al., 1999) and Xenopus (Albert et al., 1999). These results suggest that RNA pol I holoenzyme both in plants as in animals, is equipped to respond to growth and environmental signals and modify chromatin as necessary to activate transcription.

In animals, the CKII and HAT proteins involved in rRNA transcription have already been studied in detail (Voit et al., 1992; Halkidou et al., 2004), in contrast to the CKII and HAT activities in plants that remain much less characterized. However, the existence and functionality of a CKII holoenzyme has been demonstrated both in maize (Riera et al., 2004) and Arabidopsis (Salinas et al., 2006). The genome of Arabidopsis thaliana contains four CKII $\alpha$ and four CKII $\beta$ subunit genes. Three of the CKII $\alpha$ catalytic subunits localize in the nucleus and in the nucleolus (the fourth one in the chloroplast) whereas the CKII $\beta$ regulatory subunits localize either in the nucleus, in the cytoplasm or in both compartments (Salinas et al., 2006). A similar situation was 
observed in maize, where the three CKII $\beta$ subunits distributed over the cytoplasm and nucleus in contrast to the three CKII $\alpha$ subunits that remain accumulated in the nucleolus (Riera et al., 2004). Thus, the multiplicity of genes coding for $\alpha$ and $\beta$ CKII subunits in plants and differential subcellular localization may provokes a high heterogeneity of CKII that may affect both interaction with substrates and the CKII holoenzyme structure and function (Riera et al., 2004). Thus, we can speculate that distinct CKII holoenzymes are implicated either in transcription and processing of rRNA synthesis and/or other steps of ribosome biogenesis occurring in the nucleolus.

In animals and yeast cells, the nucleolar factors UBF/HmoI and TIF-1A/RRN3 play a major role in rRNA transcription (Grummt, 1999; Nomura, 2001). UBF/HmoI is an HMG protein which activates rDNA transcription by recruiting RNA pol I to the promoter, and TIF$1 \mathrm{~A} / \mathrm{RRN} 3$ is a regulatory factor that is associated with the initiation-competent subpopulation of Pol I that senses nutrient and growth-factor availability (Grummt, 1999; Nomura, 2001). So far there is no experimental evidence for a functional TIF-1A/RRN3 protein in plants, but antibodies against mammalian UBF have been shown to cross-react with a single $58 \mathrm{kDa}$ polypeptide and allow localization of an immune-related protein in the nucleolus of Allium cepa. (Rodrigo et al., 1992; De Cárcer and Medina, 1999; Tao et al., 2001a; Tao et al., 2001b). Thus, although all these data suggest that a UBF-like protein might also exist in plants; its role in rDNA transcription still has to be established. With the exception of $\mathrm{UBF} / \mathrm{HmoI}$ and TIF-1A/RRN3 genes, there are no genes coding for proteins with detectable homologies to any of the transcription factors such as TAFs, CORE or UAF identified in mammalian and yeast cells (Grummt, 1999; Nomura, 2001). Nevertheless, we can expect that genes encoding functional homologue proteins could have diverged beyond recognition in such an ancestral and unigene system. 
In contrast, different components of the nucleolar rRNA processing complex can be recognized in plants by their homology with their animal or yeast counterparts. For example, most of the genes encoding proteins that are associated with $\mathrm{C} / \mathrm{D}$ and H/ACA small nucleolar RNA (snoRNA) can be identified in the Arabidopsis genome (Brown et al., 2003b). In eukaryotic cells, the C/D and H/ACA snoRNP complexes direct rRNA base modifications at a specific position, including 5'methyl ribose methylation and 5-riboyluracil pseudouridinylation respectively (Reichow et al., 2007). Although, many snoRNAs of the types C/D and H/ACA have been identified in plants (Barneche et al., 2001; Brown et al., 2003a), only the fibrillarin/Nop1 (a C/D snoRNP) and Nap57/Cbf5p (H/ACA snoRNP), have been characterized in any detail in plants. Early studies using antibodies against human fibrillarin detected an immune-related protein in the nucleolus of onion cells (Medina et al., 1995). More recently, two genes in Arabidopsis thaliana, AtFIb1 and AtFib2, encoding nearly identical proteins conserved with eukaryotic fibrillarins were reported (Barneche et al., 2000; Pih et al., 2000). Arabidopsis Fibrillarin localizes in the nucleolus and the N-terminal glycine -and arginine -rich region is both necessary and sufficient to target AtFib1 to the nucleolus (Barneche et al., 2000; Pih et al., 2000). Later, it was shown that an Arabidopsis CBF5 like protein localizes in the nucleolus and Cajal bodies and interacts with a NAF1 protein (Lermontova et al., 2007), which is required for H/ACA snoRNP assembly (Reichow et al., 2007). The Cbf5p/NAP57 homologue is encoded by a single gene in Arabidopsis (Maceluch et al., 2001) and disruption of this gene by T-DNA insertion is lethal (Lermontova et al., 2007), demonstrating that Arabidopsis CBF5 activity is essential for viability. To our knowledge, plants with mutated or disrupted fibrillarin genes have not been described yet, and consequently how disruption of fibrillarin expression affects plant growth and development remains to be determined. Based on the expected role for AtFib proteins in ribosome biogenesis, we can anticipate that simultaneous inhibition of fibrillarin genes in thaliana would be lethal as well. Consequently, only the analysis of plants with a 
reduced level of AtFib and AtCBF, by RNAi for instance, should provide more information on the role of these two proteins in snoRNP and ribosome biogenesis in plants.

In the case of Arabidopsis, a protein named Pescadillo (AtPES) with a putative role in pre-rRNA processing was recently characterized (Zografidis et al., 2007). This protein AtPES was shown to localize in the plant nucleolus and it was able to rescue the slow growing phenotype of a yeast strain lacking the gene NOP7/YPHI. Although the role of AtPES in the nucleolus remains undefined, the nucleolar localization and experiments in yeast suggest that AtPES might be required for the formation of $25 \mathrm{~S}$ rRNA. AtPES expression is cell-cycle regulated and conforms to the major role of ribosome biogenesis in cell size and proliferation. Over-expression of AtPES does not affect plant growth and development (Zografidis et al., 2007); nevertheless we can expect any inhibition or reduction of AtPES gene expression to provoke major changes in the plant phenotype, since a single AtPES gene has been reported in the genome of Arabidopsis.

An Arabidopsis thaliana RNase III -like protein (AtRTL2) was recently reported to cleave 3'ETS sequences from pre-rRNA (Comella et al., 2008). AtRTL2 localizes in the nucleus and in the cytoplasm of Arabidopsis cells and consequently it may be involved not only in early cleavage steps of pre-rRNA in the nucleolus but also in later processing steps in the cytoplasm. Moreover, the expression of AtTL2 protein is tightly regulated to plant development. In fact, the AtRTL2 protein level decreased during seed formation and became detectable after seed imbibitions. Accumulation of different RNAs, including rRNA precursors and mRNA in seeds was reported several years ago (Aspart-Pascot et al., 1976; Aspart et al., 1980). These reports show that, whereas some RNAs are degraded during seed formation, others are stored and used as soon as germination starts. Thus, AtRTL2 transcript accumulation in dry seeds could constitute a mechanism to ensure rapid synthesis of RNase III protein for efficient growth and plant development. Interestingly, analysis of the first generation of homozygous plants, mutant for the 
AtRTL2 gene, does not display any growth defect or abnormal morphological phenotype. However, plants obtained from self pollination of Atrl2 homozygous plants showed growth and developmental defects (dwarf phenotype) that become noteworthy in the third generation (unpublished data). So far it cannot be explained how the repeated self pollination on the Atrtl2 mutant plants induces dwarf plants, but we would expect that biosynthesis of coding and/or not coding RNA(s) involved directly or indirectly in plant development is being affected.

Finally, two novel nucleolar proteins were identified in maize, which may be part of an RNP complex, MA16 and ZmDRH1 (Gendra et al., 2004). The MA16 protein is an RNA binding protein that interacts with a DEAD box RNA helicase (ZmDRH1), which in turn interacts with fibrillarin (Gendra et al., 2004). Although this observation suggests that MA16 and $\mathrm{ZmDRH} 1$ play a role in rRNA synthesis, it is also possible that these proteins, together with the fibrillarin complex, might be involved in other nucleolar activities.

A major advance, relating characterization of mechanisms controlling both transcription and pre-rRNA processing factors in plants was the identification of the Nuclear Factor $\underline{D}$ (Caparros-Ruiz et al., 1997). The NF D factor is a large U3 snoRNP complex purified from Brassica oleracea, containing snoRNAs U3 and U14, nucleolin-like protein and fibrillarin (Sáez-Vásquez et al., 2004b). Interesting, although NF D was identified by its specific interaction to 5'ETS rDNA (Caparros-Ruiz et al., 1997), the purified NF D complex also cleaved pre-rRNA at the primary cleavage site $\mathrm{P}$ in vitro (Sáez-Vásquez et al., 2004b). Thus, the NF D complex may assemble on the rDNA and subsequently bind and cleave specifically the prerRNA at the primary cleavage site (Fig. 1) (Sáez-Vásquez et al., 2004a; 2004b). A similar mechanism was also described in yeast, where a large RNP complex that contains the U3 snoRNA and 28 proteins was isolated (Dragon et al., 2002; Gallagher et al., 2004). Seventeen new proteins (Utp1-17) were present of which ten were known components, including C/D snoRNP associated proteins (Nop1, Nop56, Nop58 and snu13) and six proteins specific to U3 
snoRNP (Dragon et al., 2002). Although the Utp proteins were not reported as belonging to the NF D complex, potential functional homologues were shown to play a major role in Arabidopsis plant development (see below) (Shi et al., 2005; Griffith et al., 2007).

In this context, although several nucleolar factors involved in transcription and processing of pre-rRNA in plants have been identified either 1) throughout the characterization of functional protein complexes or 2) by homology with their animal or yeast counterparts; the functional analysis of these individual factors remains incomplete. However, the last 5 years have been particularly stimulating thanks to the description of several Arabidopsis plant mutants for nucleolar protein genes, including the multifunctional nucleolar protein nucleolin.

\section{B. Nucleolin-like proteins}

In eukaryotes cells, nucleolin is one of the most abundant non-ribosomal proteins in the nucleolus (Ginisty et al., 1999). Here, nucleolin plays a key role in the different steps involved in ribosome biogenesis, including RNA pol I transcription and processing of pre-rRNA (Roger et al., 2003), as well as assembly and nucleocytoplasmic transport of ribosome particles (Bouvet et al., 1998). Although nucleolin has been involved essentially in ribosome biogenesis, it has also been implicated in a number of additional processes that take place in the nucleus and in the cytoplasm, including maintenance of chromatin structure (Angelov et al., 2006), RNA pol II transcription regulation (Huddleson et al., 2006), DNA replication (Kim et al., 2005); mRNA stability /translation (Takagi et al., 2005) and assembly of RNP complexes (Fouraux et al., 2002; Lefebvre et al., 2002 and references therein).

Nucleolin-like proteins in plants were described early in the nineties when a nucleolinlike protein in onion cells was first identified and localized in the nucleolus (Martín et al., 1992) and in the nucleolar matrix (Mínguez and Moreno Díaz de la Espina, 1996) by using an antibody against hamster nucleolin. Other experiments in onion root cells also revealed that nucleolin and fibrillarin-like proteins co-localize during mitosis suggesting that at least a subset of RNA 
processing complexes do not disaggregate during cell division, but remain assembled and become incorporated into the new nucleolus (Cerdido and Medina, 1995). Moreover, it was shown that the onion nucleolin-like protein NopA64 (De Cárcer et al., 1997), also co-localized with an immune-related UBF protein in the dense fibrillar component surrounding the fibrillar centres of the nucleolus from onion cells (De Cárcer and Medina, 1999), suggesting that nucleolin-like protein might also be involved in transcription initiation of pre-rRNA in plants. Thus, these observation provided early evidences of a role for nucleolin in controlling both prerRNA transcription and processing.

Nucleolin -like proteins have been cloned and molecularly characterized in alfalfa (Bogre et al., 1996), pea (Tong et al., 1997) and Arabidopsis thaliana; where two nucleolin-like genes, AtNUC-L1 and AtNUC-L2, were reported (Kojima et al., 2007; Petricka and Nelson, 2007; Pontvianne et al., 2007). The nucleolin-like proteins of plants have the three distinct structural features of animal nucleolin and yeast Nsr1p protein (Ginisty et al., 1999): (a) a highly charged acidic stretch at the amino terminus with characteristic repeats; (b) two RNA Recognition Motifs (RRMs), each of which contains a highly conserved RiboNucleoProtein-1 (RNP-1) octamer motif and a less conserved RNP-2 hexamer motif; and (c) a conserved Gly- and Arg-rich carboxy-terminal sequence, designated the GAR domain. In both animals and yeast the following three regions were identified: the acidic N-terminal region, involved in interaction with components of the pre-rRNA processing complex and that may control rDNA transcription (Roger et al., 2003); the central region, that contains two or four RRM and which has been implicated in RNA binding specificity and affinity of pre-rRNA sequences (Serin et al., 1996), and the C-terminal region or GAR domain, which interacts with several ribosomal proteins (Bouvet et al., 1998) and also binds RNA but in a nonspecific manner and with low affinity (Ghisolfi et al., 1992). In plants, it has been demonstrated that the GAR domain of pea nucleolinlike protein shows DNA helicase activity (Nasirudin et al., 2005). However, the GAR domain 
seems to be less conserved in the second nucleolin-like protein in Arabidopsis, AtNUC-L2 (Pontvianne et al., 2007), suggesting that AtNUC-L2 lacks this activity.

In plants, the abundance of the nucleolin like-protein is light regulated, indicating that phytochrome may regulate the expression of this gene (Tong et al., 1997). Furthermore, a correlation of increased nucleolin -like protein expression with the cell cycle and cell proliferation was demonstrated both in pea (Reichler et al., 2001), alfalfa (Bogre et al., 1996) and onion cells (González-Camacho and Medina, 2006). More recently, it was shown that in sugar starved cells, induction of an Arabidopsis nucleolin-like protein 1 occurred with sucrose and or glucose (Kojima et al., 2007). The activity of nucleolin-like protein in plants also seems to be regulated at a post-transcriptional level. For instance, antibodies against nucleolin-like protein, cross-reacted with distinct polypeptides in protein extracts from onion (González-Camacho and Medina, 2006), alfalfa (Bogre et al., 1996), pea (Tong et al., 1997) and Arabidopsis (Kojima et al., 2007; Pontvianne et al., 2007) which suggests that these distinct polypeptides might play specific roles in controlling the multiple activities of nucleolin-like protein in plants. In fact, this is similar to nucleolin which in animals shows aberrant migration on SDS-PAGE and is highly susceptible to proteolysis (Bouche et al., 1984). Moreover, it has also been shown that in animals, the activity of nucleolin is regulated at various levels (reviewed by Tuteja and Tuteja, 1998; Srivastava and Pollard, 1999), including phosphorylation (Morimoto et al., 2002), dimethylation (Lapeyre et al., 1986) and ADP ribosylation (Leitinger and Wesierska-Gadek, 1993), glycosylation (Carpentier et al., 2005) and translation level (Kim and Srivastava, 2003; Bicknell et al., 2005). Although several potential phosphorylation sites have been identified in the sequences of nucleolin-like protein from O. sativa, M. sativa and A. thaliana (Pontvianne F. and Sáez-Vásquez J., unpublished), these putative phosphosites have not yet been tested experimentally. Consequently, the role of phosphorylation, protein cleavage and/or other protein modifications of nucleolin -like protein in plants remains uncertain. 
An exciting breakthrough regarding the function of nucleolin, not only in plants but also in higher eukaryotic organisms, comes from three recent studies in A. thaliana (Kojima et al., 2007; Petricka and Nelson, 2007; Pontvianne et al., 2007). These reports clearly demonstrate that Arabidopsis nucleolin -like proteins play a major role in growth and plant development. Analysis of three independent Arabidopsis nucleolin-like mutants, displayed reduced growth rate, a prolonged life cycle, pointed leaves, a defective vascular pattern and aberrant leaf venation (Kojima et al., 2007; Petricka and Nelson, 2007; Pontvianne et al., 2007). In addition, it was suggested that PARL (the name given by the authors to Nucleolin in Arabidopsis) might be involved in auxin dependent organ growth and patterning (Petricka and Nelson, 2007), potentially indicating a way in which nucleolin may be controlling plant development. At the molecular level, analysis of these nucleolin -like mutants revealed that the absence of the AtNUC-L1/PARL protein induces changes in the amount of unprocessed pre-rRNA at the primary cleavage site (Kojima et al., 2007; Petricka and Nelson, 2007; Pontvianne et al., 2007) and provokes nucleolar disorganization and nucleolus organizer de-condensation (Pontvianne et al., 2007). These findings show that there is a direct link between nucleolin, nucleolus structure and rRNA synthesis.

Disruption of nucleolin-like gene in Arabidopsis does not only affect synthesis of RNA pol I transcribed genes. Indeed, it was also reported that Atnuc-L1 plants exhibited a significantly reduced sugar-induced expression of ribosomal protein (RP) genes, suggesting that AtNUC-L1 might also control RNA pol II transcription (Kojima et al., 2007), as has been shown for nucleolin in animal cells (Huddleson et al., 2006). Since nutrient availability is a prerequisite for ribosome synthesis, cell growth and division (Bailey-Serres, 1998; Warner, 1999; FromontRacine et al., 2003), we can expect AtNUC-L1 to control growth and plant development by coordinating the expression of diverse factors involved in ribosome synthesis, including RPs and rRNA. In this context, an interesting observation in Atnucl-L1 plants is the induction of the 
homologous AtNUC-L2 gene expression, which is usually repressed under normal growing conditions (Pontvianne et al., 2007). Plants, in contrast to animals, contain at least two genes encoding nucleolin-like proteins, suggesting a putative specialization of this multifunctional protein in response to growth or developmental conditions. AtNUC-L2 localizes in the nucleolus of Atnucl-L1 and might rescue, at least partially, the loss of AtNUC-L1 (Pontvianne et al., 2007). Consequently, activation of AtNUC-L2 in Arabidopsis mutant plants raises questions about possible regulating mechanisms and the cellular role of AtNUC-L1 and AtNUC-L2. Answering these questions should be the next challenge in understanding the role of nucleolin-like proteins in plants.

\section{Nucleolar proteins and plant development}

The earliest reports linking nucleolar activity with plant development come from studies of Arabidopsis plants with mutated genes that encode ribosomal proteins of the small ribosome subunit. Pointed leaves and growth retardation were observed in plants mutated at the ribosomal protein loci, RPS13B (Ito et al., 2000) and RPS18A (Van Lijsebettens et al., 1994); encoding two proteins belonging to the class of early ribosome-associated proteins that assemble on the prerRNA in the nucleolus (Kressler et al., 1999). Interestingly, pointed leaves were also observed in Arabidopsis nucleolin mutants (Kojima et al., 2007; Petricka and Nelson, 2007; Pontvianne et al., 2007) suggesting the existence of a functional relationship between nucleolin and these RPs with early events in ribosome biogenesis. In agreement with this possibility, RPS13 and RPS18 proteins were detected in the proteome of the nucleolus (Pendle et al., 2005) and co-purified with nucleolin-like protein in the NF D complex fraction (Sáez-Vásquez and Echeverria, unpublished results).

Although mutations of the RPS13B and RPS18A genes do not seem to have any effect on plant survival, most likely because RP genes are encoded by only a small family of genes (Barakat et al., 2001), several other nucleolar factors have been shown to be essential in 
Arabidopsis for gametogenesis (Shi et al., 2005; Jiang et al., 2007), embryogenesis (Lahmy et al., 2004; Fleurdepine et al., 2007; Griffith et al., 2007), and central cell and endosperm development (Portereiko et al., 2006). The best characterized genes are the SLOW WALKER1 (SWA1) and TORMOZ (TOZ) genes both of which encode WD40 proteins (Shi et al., 2005; Griffith et al., 2007). The closest homologues of the SWA1 and the TOZ proteins are the yeast Utp15 and Utp13. These two yeast proteins were identified as being part of a large nucleolar U3 ribonucleoprotein complex required for $18 \mathrm{~S}$ rRNA synthesis (Dragon et al., 2002). The role of these factors in processing $18 \mathrm{~S}$ ribosomal rRNA synthesis was confirmed at least for SWA1 (Shi et al., 2005). The SYN3 gene, which encodes for a nucleolar cohesin protein, is also essential for megagametogenesis in Arabidopsis, (Jiang et al., 2007). Even though its role in the nucleolus needs to be functionally demonstrated, SYN3 protein may be involved in rDNA chromatin structure, transcription and or pre-rRNA processing (Jiang et al., 2007).

Another factor involved in plant development is the Arabidopsis La protein 1. Interestingly, the AtLa1 protein localizes in the nucleolus only in cells displaying nucleolar cavities or vacuoles. Thus, AtLa1 is the first protein known so far that accumulates in this subnucleolar compartment that seems to be plant specific. AtLa1 it is not exclusively a nucleolar protein, it localizes predominantly in the plant nucleoplasm but is excluded from the Cajal bodies (Fleurdepine et al., 2007 - S. Fleurdépine and C. Bousquet-Antonelli, unpublished results). In yeast, the AtLa1 protein was shown to be able to fulfil the functions of genuine La protein in RNA pol III primary transcript stabilization and processing, as well as in maturation and assembly of some non-coding pol II precursors such as sn- or snoRNAs. Furthermore, the AtLa1 protein has been demonstrated to bind RNA Pol III primary transcripts in planta. The AtLal defective homozygous plants display an early embryonic lethal arrest together with nucleolar hypertrophy (Fleurdepine et al., 2007). The reason for this observed altered nucleolus size in plants with a deficient AtLal function remains unaddressed but it is tempting to speculate that it 
may be linked with rRNA synthesis. Indeed, the human La protein was shown to interact with nucleolin in the dense fibrillar component (DFC), suggesting a role of hLa in the early phase of rRNA biogenesis (Intine et al., 2004). However, additional experimental analysis will be required to determine whether or not AtLa1 interacts with AtNUC-L1 in the plant nucleolus and if the AtLal defective homozygous plants display changes in the rate of transcription and processing of pre-rRNA.

An association between plant development and nucleolus hypertrophy was also observed in plants containing a T-DNA insertion in the DOMINO locus of Arabidopsis (Lahmy et al., 2004). DOMINO is a nuclear protein containing some features of nucleolar protein including an acidic region and a Gly/Arg-rich $\mathrm{C}$ terminal extension of a GAR-like domain. The dom 1 mutant plants display a larger size and a compacted nucleolus composed mainly of DFC (Lahmy et al., 2004). The role of DOMINO has not been demonstrated yet; however DOMINO is very similar to a chloroplast DCL protein of tomato which is required for chloroplast rRNA processing and correct ribosome assembly (Bellaoui and Gruissem, 2004). Enlarged or reduced nucleoli were also observed in titan (Liu Cm et al., 2002), pilz (Steinborn et al., 2002) or fem111 (Portereiko et al., 2006) mutants. TITAN and PILZ genes encode condensin and cohesin proteins involved in chromosome formation (Liu Cm et al., 2002) and in the tubulin folding cofactor required for the organization of microtubules during cell division (Steinborn et al., 2002). The fem111 mutant, on other hand, has an insertion in the Agamous-like80 (AGL80) gene which encodes a type 1 MADS domain containing protein that is required for central cell development and function. Thus, all three of these proteins can be linked in one way or another to nucleolus activity since ribosome synthesis is dependent on cell development and or division (Dez and Tollervey, 2004).

Finally, an analysis of the nucleolar proteome (http://bioinf.scri.sari.ac.uk/cgibin/atnopdb/home) and the seedgenes project (www.seedgenes.org/) of Arabidopsis reveals that at least nine embryo defective mutants correspond to gene mutations encoding nucleolar 
proteins. From this analysis it is important to mention that three genes encode for ribosomal proteins of the large ribosome subunit; RPL19 (EMB 2386), RPL3 (EMB 2207) and RPL8 (EMB 2296). In contrast to RPS13B and RPS18A plant mutants which are viable, in all three EMB mutants, embryo development was arrested at a globular embryonic stage as described for the amll (Arabidopsis Minute like-1) mutant (Weijers et al., 2001). The amll mutant has an insertion in the RPS5A gene, one of the two genes encoding for the ribosomal protein subunit RPS5, which causes semi-dominant development phenotypes in the heterozygous mutant. However, in the homozygous mutant, development is completely arrested at an early stage of development (Weijers et al., 2001). RPS5A and RPS5B are differentially expressed during embryogenesis and in the different tissues and organs these expressions do not overlap. Consequently, one functional gene copy per diploid genome might be insufficient for complete gene function. This closely resembles the situation in Drosophila Minute mutants, where for each RP gene only one functional gene is present in the genome. The RPL1, RPL3 and RPL8 are also encoded by a small family of genes, but it remains to be determined whether or not these genes are also expressed differentially. However, it is also possible that these RP proteins (and probably other nucleolar proteins belonging to small gene families) may possess additional functions to that of being a structural component of the ribosome and consequently disruption of the gene may affect a specific and essential nucleolar cellular function.

A summary of the genes from Arabidopsis thaliana which have been mentioned above as encoding nuclear and/or nucleolar proteins potentially participating in pre-rRNA synthesis and processing and ribosome assembly is shown in Table 1.

\section{Perspectives}

The history of nucleolus research is already long and it contains many outstanding milestones in the form of cytological, genetic and molecular findings of undoubted relevance, 
not only for basic life sciences, but also for applied sciences such as medicine, agriculture, food technology, etc. However, the complexity of the organelle and of the cellular functions located in it is high enough to conclude that there is still much that we don't know and that many lessons still remain hidden in the nucleolus to be uncovered and learned on fundamental aspects of gene expression and its regulation, macromolecular interactions, expression of molecular events into cellular discernible structures, relationships between cellular growth and cell proliferation, and many others. We could conclude this review indicating some of the problems that, in our opinion, could be more relevant for nucleolar research in the coming years. Certainly, the list is neither exhaustive nor unquestionable.

Whereas the discovery of nucleolar functions not linked to ribosome biogenesis (the plurifunctional nucleolus) has attracted the attention of many researchers, little is still known on the nucleolar structures associated with these novel functions, in other words, on the structural organization of these functions, actually relevant for the cellular physiology. An exciting new finding is that at least some of these functions might lay in novel nucleolar structural domains.

The unequivocal relationship of ribosome biogenesis with cell growth and proliferation makes this organelle a very efficient marker of these processes and opens the possibility of exploitation of this potentiality, mostly in studies of cellular stress caused by either biotic or abiotic agents. Although it affects to mammalian cells and not to plant cells, it would be worth mentioning here the findings on the involvement of the nucleolus in the p53 pathways. Specifically in plants, novel lines of research have shown the relationship of the nucleolus with the gravitropic response and the gravitational stress, in to the context of the effects of this stress on cell growth and proliferation.

The intriguing behaviour of the nucleolus during mitosis has still many unresolved points, such as the mechanisms of interaction of proteins with pre-rRNA in mitotic structures. 
Gene silencing processes affecting rDNA are not yet well understood, mainly concerning the selection criteria of particular NORs or subsets of rRNA genes to be silenced.

Finally, regarding nucleolar proteins, the discrimination of the nucleolar proteome of Arabidopsis, a fundamental milestone in the research field, is not totally resolved as to the functional roles played by the identified proteins there are several proteins with still unknown functions either in Arabidopsis or other eukaryotes. What is the role of these proteins in ribosome biogenesis, or in plant growth and development? Characterization studies should provide insights into the function of these proteins not only in Arabidopsis nucleolus but also in animals. Indeed, the study of molecular mechanisms involved in ribosome biogenesis in plant systems has already proven to be an excellent system in higher eukaryotic organisms.

The large number of Arabidopsis plant mutants, the development of RNAi technologies to silence one or more homologous genes and the availability of both in vitro transcription and in the pre-rRNA processing system should certainly provide new insight into the nucleolar function in plants in the coming years.

\section{Acknowledgements}

The courtesy of Dr. Pedro Esponda (CIB-CSIC, Madrid, Spain) in providing the electron microscopical images of Fig. 3, is gratefully acknowledged. Thanks to Drs. M. Devic and Dr. Cécile Bousquet-Antonelli (LGDP, Perpignan, France) for critical reading of this manuscript, and Dr. T. Roscoe and Mr. R.V. Chiverton for checking the English style. Works performed in the authors' laboratories were supported by the Centre National de la Recherche Scientifique (CNRS), by a grant from PAI "Programme d'Actions Integrées franco-espagnol", Picasso 11398VF (French team) and HF 2005-0209 (Spanish team) and by the Spanish "Plan Nacional de I+D+i” (ESP2006-13600-C02-02). 


\section{References}

Albert, A.C., Denton, M., Kermekchiev, M., and Pikaard, C.S. (1999) Histone acetyltransferase and protein kinase activities copurify with a putative Xenopus RNA polymerase I holoenzyme self-sufficient for promoter-dependent transcription. Molecular and Cellular Biology 19, 796-806.

Andersen, J.S., Lam, Y.W., Leung, A.K.L., Ong, S.E., Lyon, C.E., Lamond, A.I., and Mann, M. (2005) Nucleolar proteome dynamics. Nature 433, 77-83.

Angelier, N., Tramier, M., Louvet, E., Coppey-Moisan, M., Savino, T.M., De Mey, J.R., and Hernandez-Verdun, D. (2005) Tracking the Interactions of rRNA Processing Proteins during Nucleolar Assembly in Living Cells. Molecular Biology of the Cell 16, 28622871 .

Angelov, D., Bondarenko, V.A., Almagro, S., Menoni, H., Mongelard, F., Hans, F., Mietton, F., Studitsky, V.M., Hamiche, A., Dimitrov, S., and Bouvet, P. (2006) Nucleolin is a histone chaperone with FACT-like activity and assists remodeling of nucleosomes. Embo J. 25, 1669-1679. Epub 2006 Apr 1666.

Arellano, M., and Moreno, S. (1997) Regulation of CDK/cyclin complexes during the cell cycle. International Journal of Biochemitry and Cell Biology 29, 559-573.

Aspart-Pascot, L., Delseny, M., and Guitton, Y. (1976) Occurence of nucleoside polyphosphates in rapidly labelled RNA preparations from radish seedlings (Raphanus sativus.). Planta 131, 275-278.

Aspart, L., Cooke, R., Michaux-Ferriere, N., and Delseny, M. (1980) Ribosomal RNA synthesis in imbibing radish (Raphanus sativus) embryo axes. Planta 148, 17-23.

Azum-Gélade, M.C., Noaillac-Depeyre, J., Caizergues-Ferrer, M., and Gas, N. (1994) Cell cycle redistribution of U3 snRNA and fibrillarin. Presence in the cytoplasmic nucleolus remnant and in the prenucleolar bodies at telophase. Journal of Cell Science 107, 463475.

Bailey-Serres, J. (1998) Cytoplasmic ribosomes of higher plants. In "A look beyond transcription: Mechanisms determining mRNA stability and translation in plants." (D.R. Gallie, ed.), pp 125-144. American Society of Plant Physiologists

Barakat, A., Szick-Miranda, K., Chang, I.F., Guyot, R., Blanc, G., Cooke, R., Delseny, M., and Bailey-Serres, J. (2001) The organization of cytoplasmic ribosomal protein genes in the Arabidopsis genome. Plant Physiol 127, 398-415.

Barneche, F., Gaspin, C., Guyot, R., and Echeverria, M. (2001) Identification of 66 box C/D snoRNAs in Arabidopsis thaliana: extensive gene duplications generated multiple isoforms predicting new ribosomal RNA 2'-O-methylation sites. J Mol Biol 311, 57-73.

Barneche, F., Steinmetz, F., and Echeverria, M. (2000) Fibrillarin genes encode both a conserved nucleolar protein and a novel small nucleolar RNA involved in ribosomal RNA methylation in Arabidopsis thaliana. J Biol Chem 275, 27212-27220.

Baserga, R. (2007) Is cell size important? Cell Cycle 6, 814-816.

Bellaoui, M., and Gruissem, W. (2004) Altered expression of the Arabidopsis ortholog of DCL affects normal plant development. Planta. 219, 819-826. Epub 2004 Jun 2010.

Bernstein, K.A., and Baserga, S.J. (2004) The Small Subunit Processome Is Required for Cell Cycle Progression at G1. Molecular Biology of the Cell 15, 5038-5046.

Bernstein, K.A., Bleichert, F., Bean, J.M., Cross, F.R., and Baserga, S.J. (2007) Ribosome biogenesis is sensed at the start cell cycle checkpoint. Molecular Biology of the Cell 18, 953-964. 
Bicknell, K., Brooks, G., Kaiser, P., Chen, H., Dove, B.K., and Hiscox, J.A. (2005) Nucleolin is regulated both at the level of transcription and translation. Biochem Biophys Res Commun. 332, 817-822.

Bogre, L., Jonak, C., Mink, M., Meskiene, I., Traas, J., Ha, D.T., Swoboda, I., Plank, C., Wagner, E., Heberle-Bors, E., and Hirt, H. (1996) Developmental and cell cycle regulation of alfalfa nucMs1, a plant homolog of the yeast Nsr1 and mammalian nucleolin. Plant Cell 8, 417-428.

Boisvert, F.-M., van Koningsbruggen, S., Navascues, J., and Lamond, A.I. (2007) The multifunctional nucleolus. Nature Reviews Molecular Cell Biology 8, 574-585.

Bouche, G., Caizergues-Ferrer, M., Bugler, B., and Amalric, F. (1984) Interrelations between the maturation of a $100 \mathrm{kDa}$ nucleolar protein and pre rRNA synthesis in $\mathrm{CHO}$ cells. Nucleic Acids Res 12, 3025-3035.

Bouvet, P., Diaz, J.J., Kindbeiter, K., Madjar, J.J., and Amalric, F. (1998) Nucleolin interacts with several ribosomal proteins through its RGG domain. J Biol Chem. 273, 1902519029.

Brown, J.W., Echeverria, M., and Qu, L.H. (2003a) Plant snoRNAs: functional evolution and new modes of gene expression. Trends Plant Sci 8, 42-49.

Brown, J.W., Echeverria, M., Qu, L.H., Lowe, T.M., Bachellerie, J.P., Huttenhofer, A., Kastenmayer, J.P., Green, P.J., Shaw, P., and Marshall, D.F. (2003b) Plant snoRNA database. Nucleic Acids Res 31, 432-435.

Brown, J.W.S., Shaw, P.J., Shaw, P., and Marshall, D.V. (2005) Arabidopsis nucleolar protein database (AtNoPDB). Nucleic Acids Research 33, D633-D636.

Caparros-Ruiz, D., Lahmy, S., Piersanti, S., and Echeverria, M. (1997) Two ribosomal DNAbinding factors interact with a cluster of motifs on the $5^{\prime}$ external transcribed spacer, upstream from the primary pre-rRNA processing site in a higher plant. Eur J Biochem 247, 981-989.

Carpentier, M., Morelle, W., Coddeville, B., Pons, A., Masson, M., Mazurier, J., and Legrand, D. (2005) Nucleolin undergoes partial N- and O-glycosylations in the extranuclear cell compartment. Biochemistry. 44, 5804-5815.

Cerdido, A., and Medina, F.J. (1995) Subnucleolar location of fibrillarin and variation in its levels during the cell cycle and during differentiation of plant cells. Chromosoma 103, 625-634.

Clute, P., and Pines, J. (1999) Temporal and spatial control of cyclin B1 destruction in metaphase. Nature Cell Biology 1, 82-87.

Cmarko, D., Verschure, P.J., Rothblum, L.I., Hernandez-Verdun, D., Amalric, F., Van Driel, R., and Fakan, S. (2000) Ultrastructural analysis of nucleolar transcription in cells microinjected with 5-bromo-UTP. Histochemistry and Cell Biology 113, 181-187.

Comella, P., Pontvianne, F., Lahmy, S., Vignols, F., Barbezier, N., DeBures, A., Jobet, E., Brugidou, E., Echeverria, M., and Saez-Vasquez, J. (2008) Characterization of a ribonuclease III-like protein required for cleavage of the pre-rRNA in the 3'ETS in Arabidopsis. Nucleic Acids Research 36, 1163-1175.

Conconi, A., Sogo, J.M., and Ryan, C.A. (1992) Ribosomal gene clusters are uniquely proportioned between open and closed chromatin structures in both tomato leaf cells and exponentially growing suspension cultures. Proceedings of the National Academy of Sciences of the United States of America 89, 5256-5260.

Conconi, A., Widmer, R.M., Koller, T., and Sogo, J.M. (1989) Two different chromatin structures coexist in ribosomal RNA genes throughout the cell cycle. Cell 57, 753-761.

Chen, Z.J., and Pikaard, C.S. (1997) Epigenetic silencing of RNA polymerase I transcription: a role for DNA methylation and histone modification in nucleolar dominance. Genes and Development 11, 2124-2136. 
Chouinard, L.A. (1970) Localization of intranucleolar DNA in root meristematic cells of Allium cepa. Journal of Cell Science 6, 73-85.

Dammann, R., Lucchini, R., Koller, T., and Sogo, J.M. (1993) Chromatin structures and transcription of rDNA in yeast Saccharomyces cerevisiae. Nucleic Acids Research 21, 2331-2338.

De Cárcer, G., Cerdido, A., and Medina, F.J. (1997) NopA64, a novel nucleolar phosphoprotein from proliferating onion cells, sharing immunological determinants with mammalian nucleolin. Planta 201, 487-495.

De Cárcer, G., and Medina, F.J. (1999) Simultaneous localization of transcription and early processing markers allows dissection of functional domains in the plant cell nucleolus. Journal of Structural Biology 128, 139-151.

De la Torre, C., and Giménez-Martín, G. (1982) The nucleolar cycle. In "The nucleolus" (E.G. Jordan, and C.A. Cullis, eds), pp 153-177. Cambridge University Press. Cambridge

Deltour, R. (1985) Nuclear activation during early germination of the higher plant embryo. Journal of Cell Science 75, 43-83.

Deltour, R., and De Barsy, T. (1985) Nucleolar activation and vacuolation in embryo radicle cells during early germination. Journal of Cell Science 76, 67-83.

Dez, C., and Tollervey, D. (2004) Ribosome synthesis meets the cell cycle. Curr Opin Microbiol 7, 631-637.

Díez, J.L., Rodríguez-Vilariño, V., Medina, F.J., and Morcillo, G. (2006) Nucleolar localization of a reverse transcriptase related to telomere maintenance in Chironomus (Diptera). Histochemistry and Cell Biology 126, 445-452.

Dorée, M., and Hunt, T. (2002) From Cdc2 to Cdk1: when did the cell cycle kinase join its cyclin partner? Journal of Cell Science 115, 2461-2464.

Dragon, F., Gallagher, J.E., Compagnone-Post, P.A., Mitchell, B.M., Porwancher, K.A., Wehner, K.A., Wormsley, S., Settlage, R.E., Shabanowitz, J., Osheim, Y., Beyer, A.L., Hunt, D.F., and Baserga, S.J. (2002) A large nucleolar U3 ribonucleoprotein required for 18S ribosomal RNA biogenesis. Nature 417, 967-970.

Dundr, M., and Olson, M.O.J. (1998) Partially processed pre-rRNA is preserved in association with processing components in nucleolus-derived foci during mitosis. Molecular Biology of the Cell 9, 2407-2422.

Dundr, M., and Raska, I. (1993) Nonisotopic ultrastructural mapping of transcription sites within the nucleolus. Experimental Cell Research 208, 275-281.

Esponda, P., and Giménez-Martín, G. (1974) Cytochemical aspects of the nucleolar organizer in Allium cepa microspores. Chromosoma 45, 203-213.

Fakan, S., and Puvion, E. (1980) The ultrastructural visualization of nucleolar and extranucleolar RNA synthesis and distribution. International Review of Cytology 65, 255-295.

Flavell, R.B., O'Dell, M., and Thompson, W.F. (1988) Regulation of cytosine methylation in ribosomal DNA and nucleolus organizer expression in wheat. Journal of Molecular Biology 204, 523-534.

Fleurdepine, S., Deragon, J.M., Devic, M., Guilleminot, J., and Bousquet-Antonelli, C. (2007) A bona fide La protein is required for embryogenesis in Arabidopsis thaliana. Nucleic Acids Res. 35, 3306-3321. Epub 2007 Apr 3325.

Fouraux, M.A., Bouvet, P., Verkaart, S., van Venrooij, W.J., and Pruijn, G.J. (2002) Nucleolin associates with a subset of the human Ro ribonucleoprotein complexes. J Mol Biol. 320, 475-488.

Fromont-Racine, M., Senger, B., Saveanu, C., and Fasiolo, F. (2003) Ribosome assembly in eukaryotes. Gene 313, 17-42. 
Gallagher, J.E., Dunbar, D.A., Granneman, S., Mitchell, B.M., Osheim, Y., Beyer, A.L., and Baserga, S.J. (2004) RNA polymerase I transcription and pre-rRNA processing are linked by specific SSU processome components. Genes Dev 18, 2506-2517.

Gautier, T., Fomproix, N., Masson, C., Azum-Gélade, M.C., Gas, N., and Hernandez-Verdun, D. (1994) Fate of specific nucleolar perichromosomal proteins during mitosis: cellular distribution and association with U3 snoRNA. Biology of the Cell 82, 81-93.

Gendra, E., Moreno, A., Alba, M.M., and Pages, M. (2004) Interaction of the plant glycine-rich RNA-binding protein MA16 with a novel nucleolar DEAD box RNA helicase protein from Zea mays. Plant J. 38, 875-886.

Ghisolfi, L., Kharrat, A., Joseph, G., Amalric, F., and Erard, M. (1992) Concerted activities of the RNA recognition and the glycine-rich C-terminal domains of nucleolin are required for efficient complex formation with pre-ribosomal RNA. Eur J Biochem. 209, 541-548.

Gilbert, N., Lucas, L., Klein, C., Menager, M., Bonnet, N., and Ploton, D. (1995) Threedimensional co-location of RNA polymerase I and DNA during interphase and mitosis by confocal microscopy. Journal of Cell Science 108, 115-125.

Ginisty, H., Sicard, H., Roger, B., and Bouvet, P. (1999) Structure and functions of nucleolin. $J$ Cell Sci 112, 761-772.

Godward, M.B.E. (1950) On the nucleolus and nucleolar organizing chromosomes of Spirogyra. Annals of Botany 14, 39-53.

González-Camacho, F., and Medina, F.J. (2006) The nucleolar structure and the activity of nucleolin-like protein NopA100 during the cell cycle in proliferating plant cells. Histochemistry and Cell Biology 125, 139-153.

González-Melendi, P., Wells, B., Beven, A.F., and Shaw, P.J. (2001) Single ribosomal transcription units are linear, compacted Christmas trees in plant nucleoli. The Plant Journal 27, 223-233.

Griffith, M.E., Mayer, U., Capron, A., Ngo, Q.A., Surendrarao, A., McClinton, R., Jurgens, G., and Sundaresan, V. (2007) The TORMOZ gene encodes a nucleolar protein required for regulated division planes and embryo development in Arabidopsis. Plant Cell. 19, 22462263. Epub 2007 Jul 2246.

Grummt, I. (1999) Regulation of mammalian ribosomal gene transcription by RNA polymerase I. Prog Nucleic Acid Res Mol Biol 62, 109-154.

Guilfoyle, T.J., and Jendrisak, J.J. (1978) Plant DNA-dependent RNA polymerases: subunit structures and enzymatic properties of the class II enzymes from quiescent and proliferating tissues. Biochemistry 17, 1860-1866.

Guilfoyle, T.J., Lin, C.Y., Chen, Y.M., and Key, J.L. (1976) Purification and characterization of RNA polymerase I from a higher plant. Biochimica et Biophysica Acta 418, 344-357.

Guilfoyle, T.J., and Malcolm, S. (1980) The amounts, subunit structures, and template-engaged activities of RNA polymerases in germinating soybean axes. Developmental Biology 78, 113-125.

Halkidou, K., Logan, I.R., Cook, S., Neal, D.E., and Robson, C.N. (2004) Putative involvement of the histone acetyltransferase Tip60 in ribosomal gene transcription. Nucleic Acids Research 32, 1654-1665. Print 2004.

Hannan, R.D., Cavanaugh, A., Hempel, W.M., Moss, T., and Rothblum, L. (1999) Identification of a mammalian RNA polymerase I holoenzyme containing components of the DNA repair/replication system. Nucleic Acids Research 27, 3720-3727.

Hannan, R.D., and Rothblum, L.I. (1995) Regulation of ribosomal DNA transcription during neonatal cardiomyocyte hypertrophy. Cardiovascular Research 30, 501-510.

Heix, J., Vente, A., Voit, R., Budde, A., Michaelidis, T.M., and Grummt, I. (1998) Mitotic silencing of human rRNA synthesis: inactivation of the promoter selectivity factor SL1 by cdc2/cyclin B-mediated phosphorylation. EMBO Journal 17, 7373-7381. 
Hernandez-Verdun, D. (2006) Nucleolus: from structure to dynamics. Histochemistry and Cell Biology 125, 127-137.

Hernandez-Verdun, D., Derenzini, M., and Bouteille, M. (1982) The morphological relationship in electron microscopy between NOR-silver proteins and intranucleolar chromatin. Chromosoma 85, 461-473.

Hernandez-Verdun, D., and Gautier, T. (1994) The chromosome periphery during mitosis. BioEssays 16, 179-185.

Highett, M.I., Rawlins, D.J., and Shaw, P.J. (1993) Different patterns of rDNA distribution in Pisum sativum nucleoli correlate with different levels of nucleolar activity. Journal of Cell Science 104, 843-852.

Huddleson, J.P., Ahmad, N., and Lingrel, J.B. (2006) Up-regulation of the KLF2 Transcription Factor by Fluid Shear Stress Requires Nucleolin. Journal of Biological Chemistry 281, 15121-15128. Epub 12006 Mar 15129.

Innocente, S.A., Abrahamson, J.L.A., Cogswell, J.P., and Lee, J.M. (1999) p53 regulates a G2 checkpoint through cyclin B1. Proceedings of the National Academy of Sciences 96, 2147-2152.

International Rice Genome Sequencing Project, -. (2005) The map-based sequence of the rice genome. Nature 436, 793-800.

Intine, R.V., Dundr, M., Vassilev, A., Schwartz, E., Zhao, Y., Depamphilis, M.L., and Maraia, R.J. (2004) Nonphosphorylated human La antigen interacts with nucleolin at nucleolar sites involved in rRNA biogenesis. Mol Cell Biol. 24, 10894-10904.

Inzé, D., and De Veylder, L. (2006) Cell cycle regulation in plant development. Annual Review of Genetics 40, 77-105.

Ito, T., Kim, G.T., and Shinozaki, K. (2000) Disruption of an Arabidopsis cytoplasmic ribosomal protein S13-homologous gene by transposon-mediated mutagenesis causes aberrant growth and development. Plant J 22, 257-264.

Jiang, L., Xia, M., Strittmatter, L.I., and Makaroff, C.A. (2007) The Arabidopsis cohesin protein SYN3 localizes to the nucleolus and is essential for gametogenesis. Plant J. 50, 10201034. Epub 2007 May 1023.

Jordan, E.G. (1984) Nucleolar nomenclature. Collective report. Journal of Cell Science 67, 217 220.

Jordan, E.G. (1987) At the heart of the nucleolus. Nature 329, 489-490.

Jordan, E.G., and McGovern, J.H. (1981) The quantitative relationship of the fibrillar centres and other nucleolar components to changes in growth conditions, serum deprivation and low doses of actinomycin D in cultured diploid human fibroblasts (strain MRC-5). Journal of Cell Science 52, 373-389.

Junéra, H.R., Masson, C., Géraud, G., and Hernandez-Verdun, D. (1995) The three-dimensional organization of ribosomal genes and the architecture of the nucleoli vary with $\mathrm{G} 1, \mathrm{~S}$ and G 2 phases. Journal of Cell Science 108, 3427-3441.

Kim, K., Dimitrova, D.D., Carta, K.M., Saxena, A., Daras, M., and Borowiec, J.A. (2005) Novel checkpoint response to genotoxic stress mediated by nucleolin-replication protein a complex formation. Mol Cell Biol. 25, 2463-2474.

Kim, S.K., and Srivastava, M. (2003) Stability of Nucleolin protein as the basis for the differential expression of Nucleolin mRNA and protein during serum starvation. DNA Cell Biol 22, 171-178.

Klein, J., and Grummt, I. (1999) Cell cycle-dependent regulation of RNA polymerase I transcription: the nucleolar transcription factor UBF is inactive in mitosis and early G1. Proceedings of the National Academy of Sciences of the United States of America 96, 6096-6101. 
Kojima, H., Suzuki, T., Kato, T., Enomoto, K.-i., Sato, S., Kato, T., Tabata, S., Sáez-Vasquez, J., Echeverría, M., Nakagawa, T., Ishiguro, S., and Nakamura, K. (2007) Sugar-inducible expression of the nucleolin-1 gene of Arabidopsis thaliana and its role in ribosome synthesis, growth and development. The Plant Journal 49, 1053-1063.

Kressler, D., Linder, P., and de La Cruz, J. (1999) Protein trans-acting factors involved in ribosome biogenesis in Saccharomyces cerevisiae. Mol Cell Biol 19, 7897-7912.

Kwiatkowska, M., and Maszewski, J. (1979) Changes in the activity of RNA polymerase detected in situ and the intensity of $3 \mathrm{H}$ uridine incorporation into the nucleolus and the nucleus of interphase cells in antheridial filaments of Chara vulgaris L. Folia Histochemica et Cytochemica 17, 275-286.

Lacadena, J.R., Cermeño, M.C., Orellana, J., and Santos, J.L. (1984) Evidence for wheat-rye nucleolar competition (amphyplasty) in triticale by silver-staining procedure. Theoretical and Applied Genetics 67, 207-213.

Lahmy, S., Guilleminot, J., Cheng, C.M., Bechtold, N., Albert, S., Pelletier, G., Delseny, M., and Devic, M. (2004) DOMINO1, a member of a small plant-specific gene family, encodes a protein essential for nuclear and nucleolar functions. Plant J. 39, 809-820.

Lapeyre, B., Amalric, F., Ghaffari, S.H., Rao, S.V., Dumbar, T.S., and Olson, M.O. (1986) Protein and cDNA sequence of a glycine-rich, dimethylarginine-containing region located near the carboxyl-terminal end of nucleolin (C23 and $100 \mathrm{kDa})$. J Biol Chem. 261, 9167-9173.

Lapik, Y.R., Fernandes, C.J., Lau, L.F., and Pestov, D.G. (2004) Physical and Functional Interaction between Pes1 and Bop1 in Mammalian Ribosome Biogenesis. Molecular Cell 15, 17-29.

Lawrence, R.J., Earley, K., Pontes, O., Silva, M., Chen, Z.J., Neves, N., Viegas, W., and Pikaard, C.S. (2004) A Concerted DNA Methylation/Histone Methylation Switch Regulates rRNA Gene Dosage Control and Nucleolar Dominance. Molecular Cell 13, 599-609.

Lefebvre, S., Burlet, P., Viollet, L., Bertrandy, S., Huber, C., Belser, C., and Munnich, A. (2002) A novel association of the SMN protein with two major non-ribosomal nucleolar proteins and its implication in spinal muscular atrophy. Hum Mol Genet. 11, 1017-1027.

Leitinger, N., and Wesierska-Gadek, J. (1993) ADP-ribosylation of nucleolar proteins in HeLa tumor cells. J Cell Biochem. 52, 153-158.

Lerch-Gaggl, A., Haque, J., Li, J., Ning, G., Traktman, P., and Duncan, S.A. (2002) Pescadillo Is Essential for Nucleolar Assembly, Ribosome Biogenesis, and Mammalian Cell Proliferation. Journal of Biological Chemistry 277, 45347-45355.

Lermontova, I., Schubert, V., Bornke, F., Macas, J., and Schubert, I. (2007) Arabidopsis CBF5 interacts with the H/ACA snoRNP assembly factor NAF1. Plant Mol Biol 22, 22.

Leung, A.K., Trinkle-Mulcahy, L., Lam, Y.W., Andersen, J.S., Mann, M., and Lamond, A.I. (2006) NOPdb: Nucleolar Proteome Database. Nucleic Acids Res. 34, D218-220.

Lewis, M.S., Cheverud, J.M., and Pikaard, C.S. (2004) Evidence for Nucleolus Organizer Regions as the Units of Regulation in Nucleolar Dominance in Arabidopsis thaliana Interecotype Hybrids. Genetics 167, 931-939.

Liu Cm, C.M., McElver, J., Tzafrir, I., Joosen, R., Wittich, P., Patton, D., Van Lammeren, A.A., and Meinke, D. (2002) Condensin and cohesin knockouts in Arabidopsis exhibit a titan seed phenotype. Plant J. 29, 405-415.

Maceluch, J., Kmieciak, M., Szweykowska-Kulinska, Z., and Jarmolowski, A. (2001) Cloning and characterization of Arabidopsis thaliana AtNAP57--a homologue of yeast pseudouridine synthase Cbf5p. Acta Biochim Pol. 48, 699-709.

Martín, M., García-Fernández, L.F., Moreno Díaz de la Espina, S., Noaillac-Depeyre, J., Gas, N., and Medina, F.J. (1992) Identification and localization of a nucleolin homologue in onion nucleoli. Experimental Cell Research 199, 74-84. 
Martín, M., and Medina, F.J. (1991) A Drosophila anti-RNA polymerase II antibody recognizes a plant nucleolar antigen, RNA polymerase I, which is mostly localized in fibrillar centres. Journal of Cell Science 100, 99-107.

Martín, M., Moreno Díaz de la Espina, S., and Medina, F.J. (1989) Immunolocalization of DNA at nucleolar structural components in onion cells. Chromosoma 98, 368-377.

Medina, F.J., Cerdido, A., and De Cárcer, G. (2000) The functional organization of the nucleolus in proliferating plant cells. European Journal of Histochemistry 44, 117-131.

Medina, F.J., Cerdido, A., and Fernández-Gómez, M.E. (1995) Components of the nucleolar processing complex (pre-rRNA, fibrillarin and nucleolin) colocalize during mitosis and are incorporated to daughter cell nucleoli. Experimental Cell Research 221, 111-125.

Medina, F.J., Risueño, M.C., and Moreno Díaz de la Espina, S. (1983a) 3-D Reconstruction and morphometry of fibrillar centres in plant cells in relation to nucleolar activity. Biology of the Cell 48, 31-38.

Medina, F.J., Risueño, M.C., Rodríguez-García, M.I., and Sánchez-Pina, M.A. (1983b) The nucleolar organizer (NOR) and fibrillar centers during plant gametogenesis. Journal of Ultrastructure Research 85, 300-310.

Medina, F.J., Risueño, M.C., Sánchez-Pina, M.A., and Fernández-Gómez, M.E. (1983c) A study of nucleolar silver staining in plant cells. The role of argyrophilic proteins in nucleolar physiology. Chromosoma 88, 149-155.

Medina, F.J., Sánchez-Pina, M.A., Solanilla, E.L., Fernández-Gómez, M.E., and Risueño, M.C. (1984) Structural role of Ag-NOR proteins supported by two different nucleolar silver staining techniques. Ciência Biologica 9, 126-127.

Melcák, I., Risueño, M.C., and Raska, I. (1996) Ultrastructural nonisotopic mapping of nucleolar transcription sites in onion protoplasts. Journal of Structural Biology 116, 253-263.

Mélèse, T., and Xue, Z. (1995) The nucleolus: an organelle formed by the act of building a ribosome. Current Opinion in Cell Biology 7, 319-324.

Mínguez, A., and Moreno Díaz de la Espina, S. (1996) In situ localization of nucleolin in the plant nucleolar matrix. Experimental Cell Research 222, 171-178.

Moreno Díaz de la Espina, S. (1995) Nuclear matrix isolated from plant cells. International Review of Cytology 162B, 75-139.

Moreno Díaz de la Espina, S., Medina, F.J., and Risueño, M.C. (1980) Correlation of nucleolar activity and nucleolar vacuolation in plant cells. European Journal of Cell Biology 22, 724-729.

Moreno Díaz de la Espina, S., Risueño, M.C., Fernández-Gómez, M.E., and Tandler, C.J. (1976) Ultrastructural study of the nucleolar cycle in meristematic cells of Allium cepa. Journal de Microscopie et de Biologie Cellulaire 25, 265-278.

Morimoto, H., Okamura, H., and Haneji, T. (2002) Interaction of protein phosphatase 1 delta with nucleolin in human osteoblastic cells. J Histochem Cytochem. 50, 1187-1193.

Motte, P., Loppes, R., Menager, M., and Deltour, R. (1991) Three-dimensional electron microscopy of ribosomal chromatin in two higher plants: A cytochemical, immunocytochemical, and in situ hybridization approach. Journal of Histochemistry and Cytochemistry 39, 1495-1506.

Nasirudin, K.M., Ehtesham, N.Z., Tuteja, R., Sopory, S.K., and Tuteja, N. (2005) The Gly-Argrich C-terminal domain of pea nucleolin is a DNA helicase that catalytically translocates in the 5'- to 3'-direction. Arch Biochem Biophys. 434, 306-315.

Navashin, M. (1934) Chromosomal alterations caused by hybridization and their bearing upon certain general genetic problems. Cytologia 5, 169-203.

Nomura, M. (2001) Ribosomal RNA genes, RNA polymerases, nucleolar structures, and synthesis of rRNA in the yeast Saccharomyces cerevisiae. Cold Spring Harb Symp Quant Biol 66, 555-565. 
Olson, M.O.J. (2004) "The Nucleolus". Landes Bioscience, Georgetown, TX.

Pagnussat, G.C., Yu, H.-J., Ngo, Q.A., Rajani, S., Mayalagu, S., Johnson, C.S., Capron, A., Xie, L.-F., Ye, D., and Sundaresan, V. (2005) Genetic and molecular identification of genes required for female gametophyte development and function in Arabidopsis. Development 132, 603-614.

Panse, S.L., Masson, C., Heliot, L., Chassery, J.M., Junéra, H.R., and Hernandez-Verdun, D. (1999) 3-D organization of ribosomal transcription units after DRB inhibition of RNA polymerase II transcription. Journal of Cell Science 112, 2145-2154.

Pendle, A.F., Clark, G.P., Boon, R., Lewandowska, D., Lam, Y.W., Andersen, J., Mann, M., Lamond, A.I., Brown, J.W.S., and Shaw, P.J. (2005) Proteomic Analysis of the Arabidopsis Nucleolus Suggests Novel Nucleolar Functions. Molecular Biology of the Cell 16, 260-269.

Petricka, J.J., and Nelson, T.M. (2007) Arabidopsis Nucleolin Affects Plant Development and Patterning. Plant Physiology 144, 173-186.

Pih, K.T., Yi, M.J., Liang, Y.S., Shin, B.J., Cho, M.J., Hwang, I., and Son, D. (2000) Molecular cloning and targeting of a fibrillarin homolog from Arabidopsis. Plant Physiol. 123, 5158

Politz, J.C.R., Polena, I., Trask, I., Bazett-Jones, D.P., and Pederson, T. (2005) A Nonribosomal Landscape in the Nucleolus Revealed by the Stem Cell Protein Nucleostemin. Molecular Biology of the Cell 16, 3401-3410.

Polzikov, M., Magoulas, C., and Zatsepina, O. (2007) The nucleolar protein SURF-6 is essential for viability in mouse NIH/3T3 cells. Molecular Biology Reports 34, 155-160.

Pontvianne, F., Matía, I., Douet, J., Tourmente, S., Medina, F.J., Echeverría, M., and SáezVásquez, J. (2007) Characterization of AtNUC-L1 Reveals a Central Role of Nucleolin in Nucleolus Organization and Silencing of AtNUC-L2 Gene in Arabidopsis. Molecular Biology of the Cell 18, 369-379.

Portereiko, M.F., Lloyd, A., Steffen, J.G., Punwani, J.A., Otsuga, D., and Drews, G.N. (2006) AGL80 is required for central cell and endosperm development in Arabidopsis. Plant Cell. 18, 1862-1872. Epub 2006 Jun 1823.

Preuss, S., and Pikaard, C.S. (2007) rRNA gene silencing and nucleolar dominance: insights into a chromosome-scale epigenetic on/off switch. Biochimica et Biophysica Acta 1769, 383392

Prieto, J.L., and McStay, B. (2005) Nucleolar biogenesis: the first small steps. Biochemical Society Transactions 33, 1441-1443.

Raska, I., Koberna, K., Malinsky, J., Fidlerova, H., and Masata, M. (2004) The nucleolus and transcription of ribosomal genes. Biology of the Cell 96, 579-594.

Rawlins, D.J., and Shaw, P.J. (1990) Three-dimensional organization of ribosomal DNA in interphase nuclei of Pisum sativum by in situ hybridization and optical tomography. Chromosoma 99, 143-151.

Reeder, R.H., and Roan, J.G. (1984) The mechanism of nucleolar dominance in Xenopus hybrids. Cell 38, 39-44.

Reichler, S.A., Balk, J., Brown, M.E., Woodruff, K., Clark, G.B., and Roux, S.J. (2001) Light differentially regulates cell division and the mRNA abundance of pea nucleolin during de-etiolation. Plant Physiol 125, 339-350.

Reichow, S.L., Hamma, T., Ferre-D'Amare, A.R., and Varani, G. (2007) The structure and function of small nucleolar ribonucleoproteins. Nucleic Acids Res. 35, 1452-1464. Epub $2007 \mathrm{Feb} 1456$.

Riera, M., Figueras, M., Lopez, C., Goday, A., and Pagès, M. (2004) Protein kinase CK2 modulates developmental functions of the abscisic acid responsive protein Rab17 from 
maize. Proceedings of the National Academy of Sciences of the United States of America 101, 9879-9884.

Risueño, M.C., and Medina, F.J. (1986) "The nucleolar structure in plant cells". Cell Biology Reviews (RBC). vol. 7. University of the Basque Country-Springer International.

Risueño, M.C., Medina, F.J., and Moreno Díaz de la Espina, S. (1982) Nucleolar fibrillar centres in plant meristematic cells: ultrastructure, cytochemistry and autoradiography. Journal of Cell Science 58, 313-329.

Rodrigo, R.M., Rendon, M.C., Torreblanca, J., Garcia-Herdugo, G., and Moreno, F.J. (1992) Characterization and immunolocalization of RNA polymerase I transcription factor UBF with anti-NOR serum in protozoa, higher plant and vertebrate cells. J Cell Sci 103, 10531063.

Roger, B., Moisand, A., Amalric, F., and Bouvet, P. (2003) Nucleolin provides a link between RNA polymerase I transcription and pre-ribosome assembly. Chromosoma 111, 399-407. Epub 2003 Feb 2011.

Rose, K.M., Szopa, J., Han, F.S., Cheng, Y.C., Richter, A., and Scheer, U. (1988) Association of DNA topoisomerase I and RNA polymerase I: a possible role for topoisomerase I in ribosomal gene transcription. Chromosoma 96, 411-416.

Roussel, P., André, C., Comai, L., and Hernandez-Verdun, D. (1996) The rDNA transcription machinery is assembled during mitosis in active NORs and absent in inactive NORs. Journal of Cell Biology 133, 235-246.

Royal, A., and Simard, R. (1975) RNA synthesis in the ultrastructural and biochemical components of the nucleolus of Chinese hamster ovary cells. Journal of Cell Biology 66, 577-585.

Sacristán-Gárate, A., Navarrete, M.H., and De la Torre, C. (1974) Nucleolar development in the interphase of the cell cycle. Journal of Cell Science 16, 333-347.

Sáez-Vásquez, J., Caparros-Ruiz, D., Barneche, F., and Echeverria, M. (2004a) Characterization of a crucifer plant pre-rRNA processing complex. Biochemical Society Transactions 32, 578-580.

Sáez-Vásquez, J., Caparros-Ruiz, D., Barneche, F., and Echeverría, M. (2004b) A plant snoRNP complex containing snoRNAs, fibrillarin, and nucleolin-like proteins is competent for both rRNA gene binding and pre-rRNA processing in vitro. Molecular and Cellular Biology 24, 7284-7297.

Sáez-Vásquez, J., and Echeverría, M. (2006) Polymerase I transcription. In "Regulation of transcription in plants" (K.D. Grasser, ed.), pp. Blackwell. Oxford, UK

Sáez-Vásquez, J., Meissner, M., and Pikaard, C.S. (2001) RNA polymerase I holoenzymepromotor complexes include an associated CK2-like protein kinase. Plant Molecular Biology 47, 449-459.

Sáez-Vasquez, J., and Pikaard, C.S. (2000) RNA polymerase I holoenzyme-promoter interactions. Journal of Biological Chemistry 275, 37173-37180.

Sáez-Vásquez, J., and Pikaard, C.S. (1997) Extensive purification of a putative RNA polymerase I holoenzyme from plants that accurately initiates rRNA gene transcription in vitro. Proceedings of the National Academy of Sciences of the United States of America 94, 11869-11874.

Saez Vasquez, J., and Echeverria, M. (2006) Polymerase I transcription. In "Regulation of transcription in plants" (K.D. Grasser, ed.), pp. Blackwell. Oxford, UK

Salinas, P., Fuentes, D., Vidal, E., Jordana, X., Echeverria, M., and Holuigue, L. (2006) An Extensive Survey of CK2 $\alpha$ and $\beta$ Subunits in Arabidopsis: Multiple Isoforms Exhibit Differential Subcellular Localization. Plant and Cell Physiology 47, 1295-1308. 
Savino, T.M., Gebrane-Younes, J., De Mey, J., Sibarita, J.-B., and Hernandez-Verdun, D. (2001) Nucleolar Assembly of the rRNA Processing Machinery in Living Cells. Journal of Cell Biology 153, 1097-1110.

Scheer, U., and Rose, K.M. (1984) Localization of RNA polymerase I in interphase cells and mitotic chromosomes by light and electron microscopic immunocytochemistry. Proceedings of the National Academy of Sciences of the United States of America 81, 1431-1435.

Seither, P., Iben, S., and Grummt, I. (1998) Mammalian RNA polymerase I exists as a holoenzyme with associated basal transcription factors. Journal of Molecular Biology 275, 43-53.

Serin, G., Joseph, G., Faucher, C., Ghisolfi, L., Bouche, G., Amalric, F., and Bouvet, P. (1996) Localization of nucleolin binding sites on human and mouse pre-ribosomal RNA. Biochimie 78, 530-538.

Shaw, P.J., Highett, M.I., Beven, A.F., and Jordan, E.G. (1995) The nucleolar architecture of polymerase I transcription and processing. EMBO Journal 14, 2896-2906.

Shaw, P.J., and Jordan, E.G. (1995) The nucleolus. Annual Reviews of Cell Biology 11, 93-121.

Shi, D.Q., Liu, J., Xiang, Y.H., Ye, D., Sundaresan, V., and Yang, W.C. (2005) SLOW WALKER1, essential for gametogenesis in Arabidopsis, encodes a WD40 protein involved in 18S ribosomal RNA biogenesis. Plant Cell. 17, 2340-2354. Epub 2005 Jun 2324.

Sirri, V., Hernandez-Verdun, D., and Roussel, P. (2002) Cyclin-dependent kinases govern formation and maintenance of the nucleolus. Journal of Cell Biology 156, 969-981.

Sirri, V., Roussel, P., and Hernandez-Verdun, D. (1999) The mitotically phosphorylated form of the transcription termination factor TTF-1 is associated with the repressed rDNA transcription machinery. Journal of Cell Science 112, 3259-3268.

Sirri, V., Roussel, P., and Hernandez-Verdun, D. (2000) In vivo release of mitotic silencing of ribosomal gene transcription does not give rise to precursor ribosomal RNA processing. Journal of Cell Biology 148, 259-270.

Srivastava, M., and Pollard, H.B. (1999) Molecular dissection of nucleolin's role in growth and cell proliferation: new insights. FASEB Journal 13, 1911-1922.

Steinborn, K., Maulbetsch, C., Priester, B., Trautmann, S., Pacher, T., Geiges, B., Kuttner, F., Lepiniec, L., Stierhof, Y.D., Schwarz, H., Jurgens, G., and Mayer, U. (2002) The Arabidopsis PILZ group genes encode tubulin-folding cofactor orthologs required for cell division but not cell growth. Genes Dev. 16, 959-971.

Takagi, M., Absalon, M.J., McLure, K.G., and Kastan, M.B. (2005) Regulation of p53 translation and induction after DNA damage by ribosomal protein L26 and nucleolin. Cell. 123, 49-63.

Tao, W., Xu, W., Valdivia, M.M., Hao, S., and Zhai, Z.H. (2001a) Distribution and transcription activity of nucleolar DNA in higher plant cells. Cell Biol Int 25, 1167-1171.

Tao, W., Yan, C.H., Cai, T., Hao, S., and Zhai, Z.H. (2001b) Structural components of the nuclear body in nuclei of Allium cepa cells. Cell Res 11, 68-73.

Testillano, P.S., Gorab, E., and Risueño, M.C. (1994) A new approach to map transcription sites at the ultrastructural level. Journal of Histochemistry and Cytochemistry 42, 1-10.

Testillano, P.S., Sánchez-Pina, M.A., Olmedilla, A., Ollacarizqueta, M.A., Tandler, C.J., and Risueño, M.C. (1991) A specific ultrastructural method to reveal DNA: The NAMA- Ur. Journal of Histochemistry and Cytochemistry 39, 1427-1438.

The Arabidopsis Genome Initiative, -. (2000) Analysis of the genome sequence of the flowering plant Arabidopsis thaliana. Nature 408, 796-815. 
Thiry, M., Cheutin, T., O'Donohue, M.F., Kaplan, H., and Ploton, D. (2000) Dynamics and three-dimensional localization of ribosomal RNA within the nucleolus. RNA-A Publication of the RNA Society 6, 1750-1761.

Thiry, M., and Goessens, G. (1996) "The nucleolus during the cell cycle". Landes Bioscience, Georgetown, TX.

Thompson, W.F., Beven, A.F., Wells, B., and Shaw, P.J. (1997) Sites of rDNA transcription are widely dispersed through the nucleolus in Pisum sativum and can comprise single genes. The Plant Journal 12, 571-581.

Thompson, W.F., and Flavell, R.B. (1988) DNase I sensitivity of ribosomal RNA genes in chromatin and nucleolar dominance in wheat. Journal of Molecular Biology 204, 535548 .

Tong, C.G., Reichler, S., Blumenthal, S., Balk, J., Hsieh, H.L., and Roux, S.J. (1997) Light regulation of the abundance of mRNA encoding a nucleolin-like protein localized in the nucleoli of pea nuclei. Plant Physiol 114, 643-652.

Tuteja, R., and Tuteja, N. (1998) Nucleolin: a multifunctional major nucleolar protein. CRC Crit.Rev.Biochem.Mol.Biol. 33, 407-436.

Van Lijsebettens, M., Vanderhaeghen, R., De Block, M., Bauw, G., Villarroel, R., and Van Montagu, M. (1994) An S18 ribosomal protein gene copy at the Arabidopsis PFL locus affects plant development by its specific expression in meristems. Embo J 13, 3378-3388.

Voit, R., Hoffmann, M., and Grummt, I. (1999) Phosphorylation by G1-specific cdk-cyclin complexes activates the nucleolar transcription factor UBF. EMBO Journal 18, 18911899.

Voit, R., Schnapp, A., Kuhn, A., Rosenbauer, H., Hirschmann, P., Stunnenberg, H.G., and Grummt, I. (1992) The nucleolar transcription factor mUBF is phosphorylated by casein kinase II in the C-terminal hyperacidic tail which is essential for transactivation. EMBO Journal 11, 2211-2218.

Warner, J.R. (1999) The economics of ribosome biosynthesis in yeast. Trends in Biochemical Sciences 24, 437-440.

Weijers, D., Franke-van Dijk, M., Vencken, R.J., Quint, A., Hooykaas, P., and Offringa, R. (2001) An Arabidopsis Minute-like phenotype caused by a semi-dominant mutation in a ribosomal protein S5 gene. Development 128, 4289-4299.

Zografidis, A., Kapolas, G., Kitsios, G., McCann, M., Roberts, K., Milioni, D., and Haralampidis, K. (2007) Isolation and characterization of ZePES and AtPES, the pescadillo orthologs from Zinnia and Arabidopsis. Plant Science 173, 358-369. 


\section{Protein gene}

\section{AtFib1}

AtFib2

AtNAP57

AtNAF1

AtPes

AtNUC-L1/PARL1

AtNUC-L2

TOZ

SWA1

EDA14/UTP11

AtRTL2

AtLa1

DOMINO1

TITAN/AtSM2

PILZ/POR

AGLM80/FEM111

SYN3

PFL1

\section{PFL2}

AtRPS5/AML1

At $\alpha A$

At $\alpha B$

At $\alpha \mathrm{C}$

At $\beta 1$

At $\beta 2$

At $\beta 3$
AGI number Similarity

At5g52470 Fibrillarin/Nop1p rRNA methylation

At4g25630 Fibrillarin/Nop1p

At3g57150 CBF5/NAP57

At1g03530

NAF1

At5g14520

Pescadillo/Nop7p

Nucleolin/Nsr1p

At3g18610 Nucleolin/Nsr1p

At5g 16750

At2g47990

At3g60360

At3g20420

At4g32720

At5g62440

At3g47460

At4g39920

At5g48670

At3g59550

At1g22780

At4g00100

At3g11940

At5g67380

At3g50000

At2g23080

At5g47080

At4g17640

At3g60250
Utp15 -like protein

Utp13 -like protein

RNasellI

La -like proteins

DCL

Condensin -like protein

tubulin folding cofactor

MADS domain protein

Cohesin -like protein

RPS18A

RPS13B

RPS5A

$\alpha \mathrm{CK} 2$ subunit

$\alpha \mathrm{CK} 2$ subunit

$\alpha \mathrm{CK} 2$ subunit

$\beta C K 2$ subunit

$\beta C K 2$ subunit
Utp11 -like protein

$\beta C K 2$ subunit
Function

rRNA methylation

Pseudourydilation

H/ACA assembly

25S rRNA synthesis

Ribosome biogenesis

Ribosome biogenesis

18S rRNA synthesis

18S rRNA synthesis

18S rRNA synthesis

3'ETS pre-rRNA processing

RNA synthesis

Nucleolus size

Nucleolus size

Nucleolus size

Nucleolus size

Chromatin structure, synthesis of rRNA?

Small subunit ribosomal protein

Small subunit ribosomal protein

Small subunit ribosomal protein

Casein kinase 2

Phosphorylation of transcription and pre-RNA processing factors
References

Barneche et al., 2000; Pih et al., 2000

Barneche et al., 2000;

Maceluch et al, 2001

Lermontova et al., 2007

Zografidis et al., 2007

Pontvianne et al., 2007; Kojima et al., 2007; Petricka et al., 2007

Pontvianne et al., 2007; Kojima et al., 2007

Griffith et al., 2007

Shi et al., 2005

Pagnussat et al., 2005

Comella et al., 2008

Fleurdépine et al., 2007

Lahmy et al., 2004

Liu et al., 2002

Steinborn et al., 2007

Portereiko et al., 2006

Jiang et al., 2007

Van Lijsebettens et al., 1994

Ito et al., 2000

Weijers et al., 2001

Saez-Vasquez et al., 2001; Salinas et al., 2006

Table 1: Reported Arabidopsis thaliana genes encoding nuclear and/or nucleolar proteins with potential function in rRNA synthesis or ribosome biogenesis 


\section{Legends for the Figures}

Figure 1. Schematic representation of a Nucleolar Organizer Region (NOR), shown as a segment of a specific chromosome (the centromere is indicated). A part of the NOR is structured as a knob of condensed chromatin, whereas the rest forms an extended loop of ribosomal DNA genes (rDNA genes) from which the nucleolus originates. The NOR is made up of hundreds or thousands (depending on the species) of rDNA genes arrayed in head to tail tandem repeats containing the $18 \mathrm{~S}$, the $5.8 \mathrm{~S}$ and $25 \mathrm{~S}$ ribosomal RNA (rRNA). The loop contains focal concentrations of rDNA - fibrillar centres -, around which transcription is organized. The rDNA gene units are transcribed by the RNA polymerase I (RNA pol I) and a subset of rRNA transcriptional factors as an rRNA precursor (pre-rRNA) containing external transcribed spacers (5'ETS and 3'ETS) and internal transcribed spacers (ITS1 and ITS2). The mature 18S, 5.8S and $25 \mathrm{~S}$ ribosomal RNA are obtained after a series of pre-rRNA processing steps including base modification (methylation by C/D snoRNP and pseudouridinylation by H/ACA snoRNP) and endo- and exo-nucleolytic steps to remove the ETS and ITS. Arrows indicate transcription initiation sites. The primary cleavage sites $(\mathrm{P})$ in the 5 , ETS of pre-rRNA in crucifer plants is indicated.

Figure 2. Active nucleoli from a root meristematic cell of Allium cepa (a), from a suspension cultured cell of Medicago sativa (b), and from a suspension cultured cell of Arabidopsis thaliana (c). The same nucleolar subcomponents are present in the three species, and their arrangement is also very similar, corresponding to analogous physiological situations. FC: Fibrillar Centre; DFC: Dense Fibrillar Component; GC: Granular Component; V: Vacuole. Bars indicate $1 \mu \mathrm{m}$.

Figure 3. The nucleolus of Allium cepa microspores during postmeiotic reactivation of the nucleolar functions. ( $a$ and $b$ ): Glutaraldehyde/osmium fixation and uranyl/lead staining. a: Young microspore. Two balls of Dense Fibrillar Component (DFC) are symmetrically arranged with respect to the Nucleolar Organizer Region (NOR) whose structure is the same as that of the heterogeneous fibrillar centres, and whose activity is kept at very low levels. b: Microspore at a more advanced stage. In addition to a general enlargement, the DFC balls and the NOR show an irregular shape and, within the NOR, the structure is homogeneous, after decondensation of the small inclusions of condensed chromatin. (c and d): EDTA regressive staining. The chromatin (chr) is bleached and RNP-containing structures are preferentially stained. Within the NOR, some contrasted fibrils are seen (small arrows in d) at the periphery of the bleached chromatin 
inclusions. e: RNase digestion. The RNP components have been removed, among them the fibrils stained by the EDTA method, located among condensed chromatin inclusions in the NOR. DFC: Dense fibrillar component. NOR: Nucleolar organizing region. chr: chromatin. Unless otherwise expressed, bars indicate $1 \mu \mathrm{m}$. Courtesy of Dr. Pedro Esponda, CIB-CSIC, Madrid, Spain.

Figure 4. Schematic view of the evolution of the nucleolar structural components throughout the cell cycle. At the end of interphase, the active nucleolus is made up of territories of dense fibrillar component with fibrillar centres embedded in them, all of them surrounded by a granular component. Entry in mitosis involves condensation of chromatin to form chromosomes (chr), nuclear envelope breakdown, and arrest of nucleolar activity, leading to the dispersion of the granular component, followed by that of the dense fibrillar component, and coalescence of fibrillar centres (Prophase). In metaphase, the nucleolus is not visible as a differentiated organelle. Chromosomes (chr) are at the equatorial plate, ribosomal genes are gathered at the NOR and chromosomes appear surrounded by a perichromosomal sheath, whose internal structure resembles the dense fibrillar component. This organization is maintained at anaphase, when chromosomes migrate to the poles. In telophase, chromosomes (chr) decondense and the material of the perichromosomal sheath forms prenucleolar bodies (PNBs), whose materials, in turn, are recruited at the NOR, which resumes its transcriptional activity. As a result of these two processes, the new nucleolus is progressively enlarged. In G1, in each of the two daughter cells, the nucleolar activity gradually increases, and the granular component begins to be observed.

Figure 5. Nucleolar models in the different interphase periods. The relative nucleolar size, as well as the distribution of the nucleolar structural subcomponents in each period, are shown. Morphological and morphometrical features correlate to the rate of nucleolar transcriptional and processing activity. From González-Camacho and Medina (2006). Reproduced with permission of the publisher (Springer). 


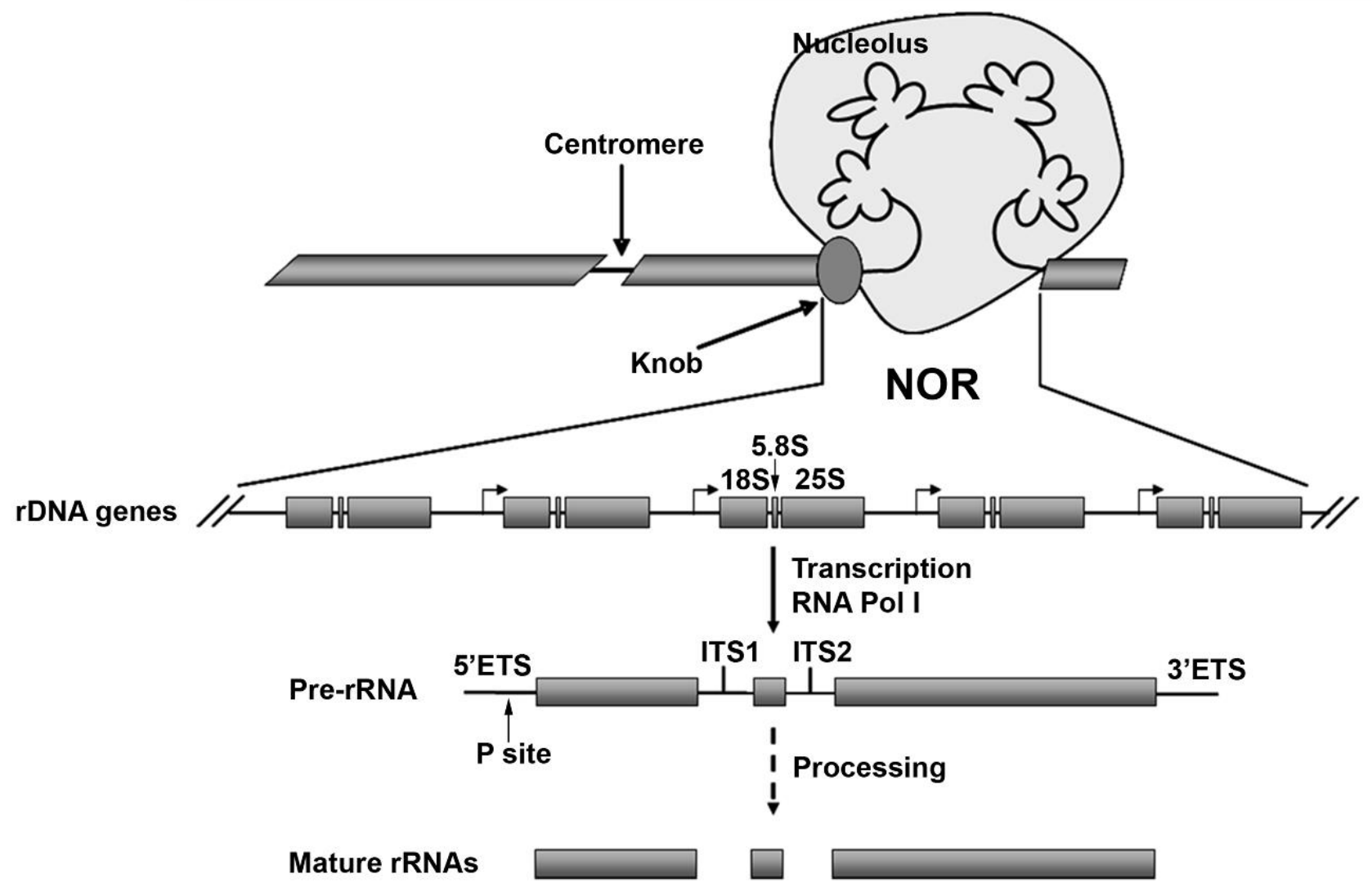

Figure 1. Schematic representation of a Nucleolar Organizer Region (NOR), shown as a segment of a specific chromosome (the centromere is indicated). A part of the NOR is structured as a knob of condensed chromatin, whereas the rest forms an extended loop of ribosomal DNA genes (rDNA genes) from which the nucleolus originates. The NOR is made up of hundreds or thousands (depending on the species) of rDNA genes arrayed in head to tail tandem repeats containing the $18 \mathrm{~S}$, the $5.8 \mathrm{~S}$ and $25 \mathrm{~S}$ ribosomal RNA ( $\mathrm{rRNA}$ ). The loop contains focal concentrations of rDNA - fibrillar centres -, around which transcription is organized. The rDNA gene units are transcribed by the RNA polymerase I (RNA pol I) and a subset of rRNA transcriptional factors as an rRNA precursor (pre-rRNA) containing external transcribed spacers (5'ETS and 3'ETS) and internal transcribed spacers (ITS1 and ITS2). The mature 18S, 5.8S and 25S ribosomal RNA are obtained after a series of pre-rRNA processing steps including base modification (methylation by C/D snoRNP and pseudouridinylation by H/ACA snoRNP) and endo- and exo-nucleolytic steps to remove the ETS and ITS. Arrows indicate transcription initiation sites. The primary cleavage sites $(P)$ in the $5^{\prime}$ ETS of pre-rRNA in crucifer plants is indicated. 

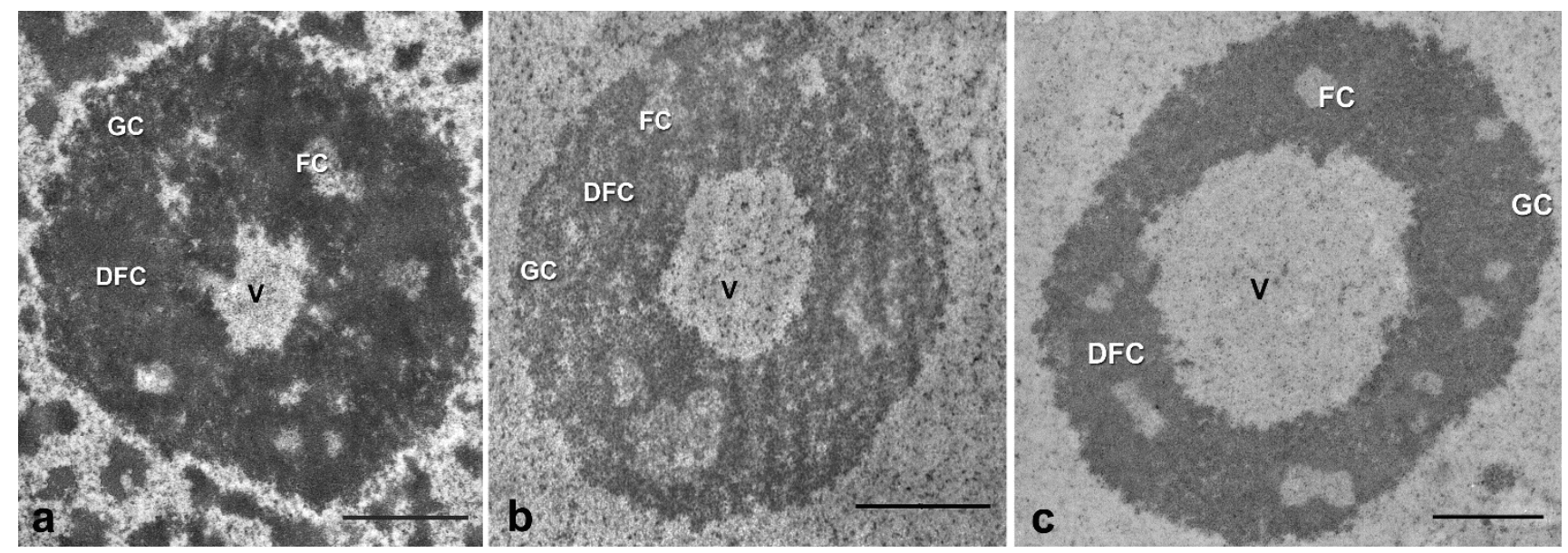

Figure 2. Active nucleoli from a root meristematic cell of Allium cepa (a), from a suspension cultured cell of Medicago sativa (b), and from a suspension cultured cell of Arabidopsis thaliana (c). The same nucleolar subcomponents are present in the three species, and their arrangement is also very similar, corresponding to analogous physiological situations. FC: Fibrillar Centre; DFC: Dense Fibrillar Component; GC: Granular Component; V: Vacuole. Bars indicate $1 \mu \mathrm{m}$. 

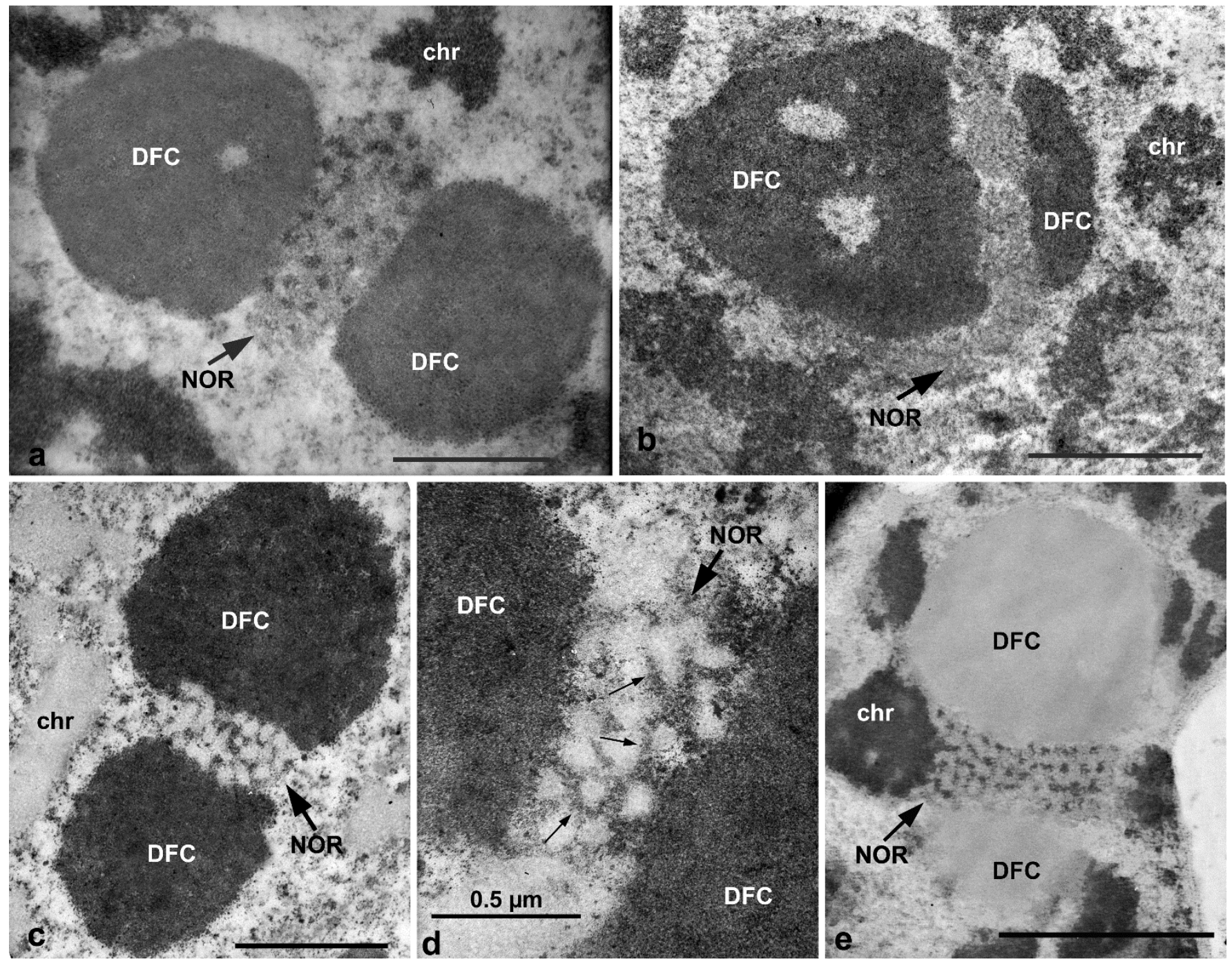

Figure 3. The nucleolus of Allium cepa microspores during postmeiotic reactivation of the nucleolar functions. ( $a$ and $b$ ): Glutaraldehyde/osmium fixation and uranyl/lead staining. a: Young microspore. Two balls of Dense Fibrillar Component (DFC) are symmetrically arranged with respect to the Nucleolar Organizer Region (NOR) whose structure is the same as that of the heterogeneous fibrillar centres, and whose activity is kept at very low levels. b: Microspore at a more advanced stage. In addition to a general enlargement, the DFC balls and the NOR show an irregular shape and, within the NOR, the structure is homogeneous, after decondensation of the small inclusions of condensed chromatin. (c and d): EDTA regressive staining. The chromatin (chr) is bleached and RNP-containing structures are preferentially stained. Within the NOR, some contrasted fibrils are seen (small arrows in d) at the periphery of the bleached chromatin inclusions. e: RNase digestion. The RNP components have been removed, among them the fibrils stained by the EDTA method, located among condensed chromatin inclusions in the NOR. DFC: Dense fibrillar component. NOR: Nucleolar organizing region. chr: chromatin. Unless otherwise expressed, bars indicate $1 \mu \mathrm{m}$. Courtesy of Dr. Pedro Esponda, CIBCSIC, Madrid, Spain. 


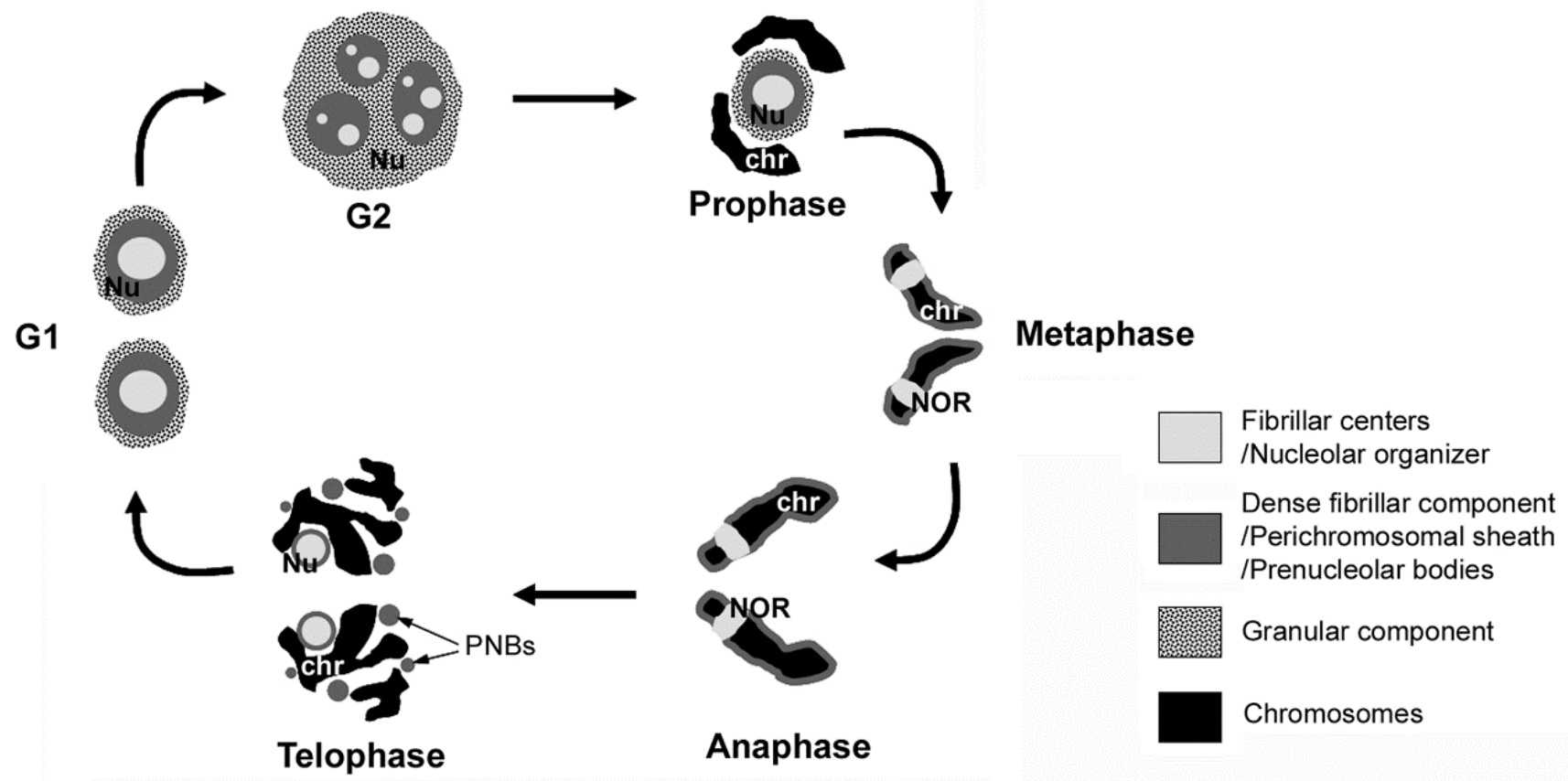

Figure 4. Schematic view of the evolution of the nucleolar structural components throughout the cell cycle. At the end of interphase, the active nucleolus is made up of territories of dense fibrillar component with fibrillar centres embedded in them, all of them surrounded by a granular component. Entry in mitosis involves condensation of chromatin to form chromosomes (chr), nuclear envelope breakdown, and arrest of nucleolar activity, leading to the dispersion of the granular component, followed by that of the dense fibrillar component, and coalescence of fibrillar centres (Prophase). In metaphase, the nucleolus is not visible as a differentiated organelle. Chromosomes (chr) are at the equatorial plate, ribosomal genes are gathered at the NOR and chromosomes appear surrounded by a perichromosomal sheath, whose internal structure resembles the dense fibrillar component. This organization is maintained at anaphase, when chromosomes migrate to the poles. In telophase, chromosomes (chr) decondense and the material of the perichromosomal sheath forms prenucleolar bodies (PNBs), whose materials, in turn, are recruited at the NOR, which resumes its transcriptional activity. As a result of these two processes, the new nucleolus is progressively enlarged. In G1, in each of the two daughter cells, the nucleolar activity gradually increases, and the granular component begins to be observed. 


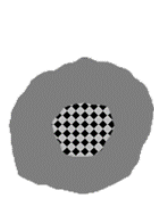

G0

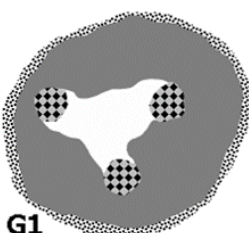

G1

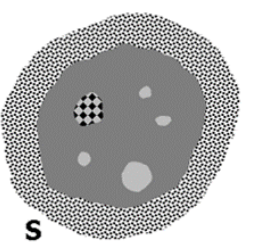

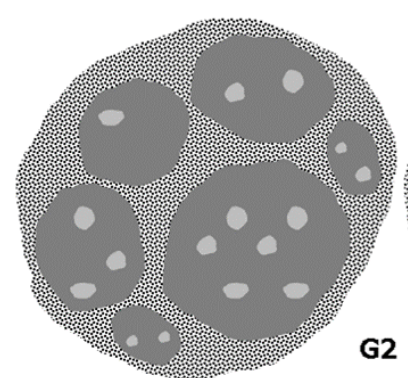

G2

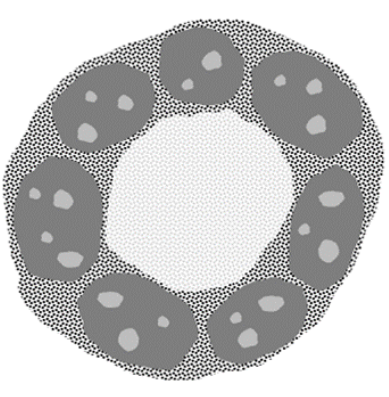

Dense Fibrilla

Granular

Homogeneous

Heterogeneous ..... Fibrillar centers $\square$ Nucleolar vacuole

Nucleolar Vacuole
of G2

Figure 5. Nucleolar models in the different interphase periods. The relative nucleolar size, as well as the distribution of the nucleolar structural subcomponents in each period, are shown.

Morphological and morphometrical features correlate to the rate of nucleolar transcriptional and processing activity. From González-Camacho and Medina (2006). Reproduced with permission of the publisher (Springer). 